\title{
The Impact of the North Atlantic Oscillation on Renewable Energy Resources in Southwestern Europe
}

\author{
S. Jerez, ${ }^{*}$ R. M. Trigo, ${ }^{*+}$ S. M. Vicente-Serrano, ${ }^{\#}$ D. Pozo-VÁzQuez, ${ }^{@}$ R. Lorente-Plazas, ${ }^{\&}$ \\ J. LORENZO-LACRUZ, ${ }^{\#}$ F. SANTOS-ALAMILlOS, ${ }^{@}$ AND J. P. MONTÁVEZ ${ }^{\&}$ \\ * Instituto Dom Luiz, Universidade de Lisboa, Lisbon, Portugal \\ ${ }^{+}$Departamento de Engenharias, Universidade Lusófona, Lisbon, Portugal \\ "Instituto Pirenaico de Ecología (CSIC), Zaragoza, Spain \\ @ Departamento de Física, Universidad de Jaén, Jaén, Spain \\ ${ }^{\&}$ Departamento de Física, Universidad de Murcia, Murcia, Spain
}

(Manuscript received 18 September 2012, in final form 18 April 2013)

\begin{abstract}
Europe is investing considerably in renewable energies for a sustainable future, with both Iberian countries (Portugal and Spain) promoting significantly new hydropower, wind, and solar plants. The climate variability in this area is highly controlled by just a few large-scale teleconnection modes. However, the relationship between these modes and the renewable climate-dependent energy resources has not yet been established in detail. The objective of this study is to evaluate the impact of the North Atlantic Oscillation (NAO) on the interannual variability of the main and primary renewable energy resources in Iberia. This is achieved through a holistic assessment that is based on a 10-km-resolution climate simulation spanning the period 1959-2007 that provides physically consistent data of the various magnitudes involved. A monthly analysis for the extended winter (October-March) months shows that negative NAO phases enhance wind speeds (10\%-15\%) and, thereby, wind power (estimated around 30\% at typical wind-turbine altitudes) and hydropower resources (with changes in precipitation exceeding $100 \%$ and implying prolonged responses in reservoir storage and release throughout the year), while diminishing the solar potential $(10 \%-20 \%)$. Opposite signals were also sporadically identified, being well explained when taking into account the orography and the prevailing wind direction during both NAO phases. An additional analysis using real wind, hydropower, and solar power generation data further confirms the strong signature of the NAO.
\end{abstract}

\section{Introduction}

To promote a sustainable future, Europe allocates large amounts of public and private investment money to renewable energy power plants as part of both 1) mitigation and adaptation strategies to the current climate change affecting with particular intensity the western sector of the Mediterranean Sea basin (Giorgi 2006) and 2) economic development and energetic independence plans allowing for reductions in expensive imports of nonrenewable resources (Patel 2011). Both Iberian countries, Portugal and Spain, are especially sensitive and committed to these concerns, having increasingly funded hydropower, wind, and, more

Corresponding author address: Sonia Jerez, IDL, Faculdade de Ciências, Universidade de Lisboa, Geofísica, Campo Grande, Bldg. C8, 3rd Fl., Lisbon 1749-016, Portugal.

E-mail: sonia.jerez@gmail.com recently, solar plants (Campo 1992; Stenzel and Frenzel 2008; Caldés et al. 2009). Hydropower (HP; definitions of some of the key acronyms used in this paper also appear in appendix B for ready reference) is the most mature and productive renewable energy source in Iberia, as it was developed in large-scale between the 1950s and 1980s. Nowadays, it provides roughly $30 \%$ $(20 \%)$ of all electricity production in Portugal (Spain) in an average year. Wind power (WP) ranks second among the renewable energy options, having received the largest amount of investment in the last decade and being close to achieving a mature status. By the end of 2011, Spain and Portugal had installed roughly 20000 and $4000 \mathrm{MW}$, respectively, of WP capacity and during the year 2011 both countries produced roughly $15 \%$ of their total electricity from wind origins. Finally, Iberia holds some of the largest photovoltaic plants in the world, namely Moura (45 MW) and Seville (60 MW). Currently, Spain is second in the world ranking of solar 
TABLE 1. Power installed (MW) per technology within the special regime in Spain from 2007 to 2011. The last column depicts the growth from 2010 to 2011 as a percentage. The special regime involves installations with power capacity below 50 MW that use either renewable energy sources or nonrenewable energy sources but including high-efficiency technologies. Here, PV indicates photovoltaic and CSP denotes concentrated solar power. (Source: http://www.ree.es/, 2011 report.)

\begin{tabular}{|c|c|c|c|c|c|c|}
\hline Technology & 2007 & 2008 & 2009 & 2010 & 2011 & $2010 \rightarrow 2011(\%)$ \\
\hline Total renewable & 16573 & 21814 & 24933 & 26688 & 29085 & 9.0 \\
\hline Hydraulic & 1871 & 1979 & 2022 & 2035 & 2041 & 0.3 \\
\hline Wind power & 13529 & 15977 & 18712 & 19710 & 21091 & 7.0 \\
\hline Solar power (PV) & 612 & 3207 & 3249 & 3657 & 4047 & 10.7 \\
\hline Solar power (CSP) & 11 & 61 & 232 & 532 & 1049 & 97.1 \\
\hline Biomass & 395 & 422 & 535 & 555 & 650 & 17.2 \\
\hline Biogas & 155 & 167 & 183 & 198 & 208 & 5.1 \\
\hline Total nonrenewable & 6543 & 6803 & 7024 & 7187 & 7282 & 1.3 \\
\hline Residual heat & 67 & 67 & 68 & 68 & 68 & 0.0 \\
\hline Mineral products & 350 & 350 & 335 & 335 & 332 & -0.9 \\
\hline Fuel & 966 & 966 & 938 & 916 & 878 & -4.1 \\
\hline Municipal solid waste & 234 & 234 & 234 & 234 & 208 & -11.3 \\
\hline Natural gas & 4924 & 5185 & 5449 & 5634 & 5797 & 2.9 \\
\hline
\end{tabular}

energy producers, just behind Germany. Although the relative contribution in Iberia of solar power (SP) to the annual electricity production is still small, in the foreseeable future it is expected to grow substantially, following the trends in recent years (see Table 1).

Resource evaluation is a mandatory requisite for the success of such a large amount of investment and expectations. As the life span of most renewable energy plants is up to several decades, this type of evaluation should include estimations of the interannual variability of the resources. However, more often than not, the evaluation of these weather and climate-dependent resources is based on in-field measurements collected at temporary meteorological stations having only a few years of data, which hinders our ability to adequately compete the interannual variability. Moreover, instrumental databases omit many areas. Climate models constitute a useful tool for bridging the gap between the needs and the potential of the instrumental records, providing long, spatially homogeneous and comprehensive datasets, thus enabling us to adopt holistic approaches. In particular, reanalysis data and their regionalization over high-resolution grids through the use of regional climate models are widely used to characterize the present-day conditions (Wernli and Schwierz 2006; Tapiador 2009; Herrera et al. 2010).

Both observations and model-based studies have widely established the great influence that the North Atlantic Oscillation (NAO) exercises on the European climate, especially in western Europe during wintertime (Hurrell 1995; Hurrell and Van Loon 1997; Osborn et al. 1999; Wanner et al. 2001; Trigo et al. 2002, 2004, 2008; Trigo 2006; López-Moreno and Vicente-Serrano 2008). This large-scale mode of climate variability consists of a meridional gradient in sea level pressure over the
North Atlantic Ocean. During its positive phases, high pressure dominates in the Atlantic sector around the Azores Islands with low pressure over northern regions near Iceland, promoting westerly winds in northern Europe and northerly winds over Iberia (Fig. 1a). Such a dipole in sea level pressure disappears during negative NAO phases (Fig. 1b), which implies weaker westerly winds in northern Europe while the wind blows faster and at a nearly right angle over the western Iberian Peninsula (IP) coastline, advecting humid air from the ocean and thereby enhancing cloudiness and precipitation over most of Iberia (which is also due to the associated fact that cyclones follow a more southern path).

These NAO-related impacts on the wind field, cloudiness, and precipitation should affect the renewable energy potential. In fact, several studies have been developed examining the impact of the NAO on HP-related variables such as river flow and water storage (Trigo et al. 2004; López-Moreno et al. 2007; Lorenzo-Lacruz et al. 2011), as well as the radiation budget (Pozo-Vázquez et al. 2004, 2011) and the wind resource (Martín et al. 2010, 2011; Pozo-Vázquez et al. 2011). However, none of these previous works adopted as detailed and holistic approaches as are undertaken here, thus being hardly applicable for the success of the energy policies and the expected massive development of renewable energy plants in the coming decades in Iberia.

Therefore, the objective of the present study is to provide a comprehensive spatiotemporal evaluation of the impact of the NAO on the variability of the hydropower, wind, and solar resources in the IP. This has been performed from the advantageous perspective of a highresolution $(10 \mathrm{~km})$, lengthy (almost five decades in the recent past), and multivariable hindcast dataset. The 


\section{a) Winter (Oct.-to-Mar.), NAO+, SLP \& W10}

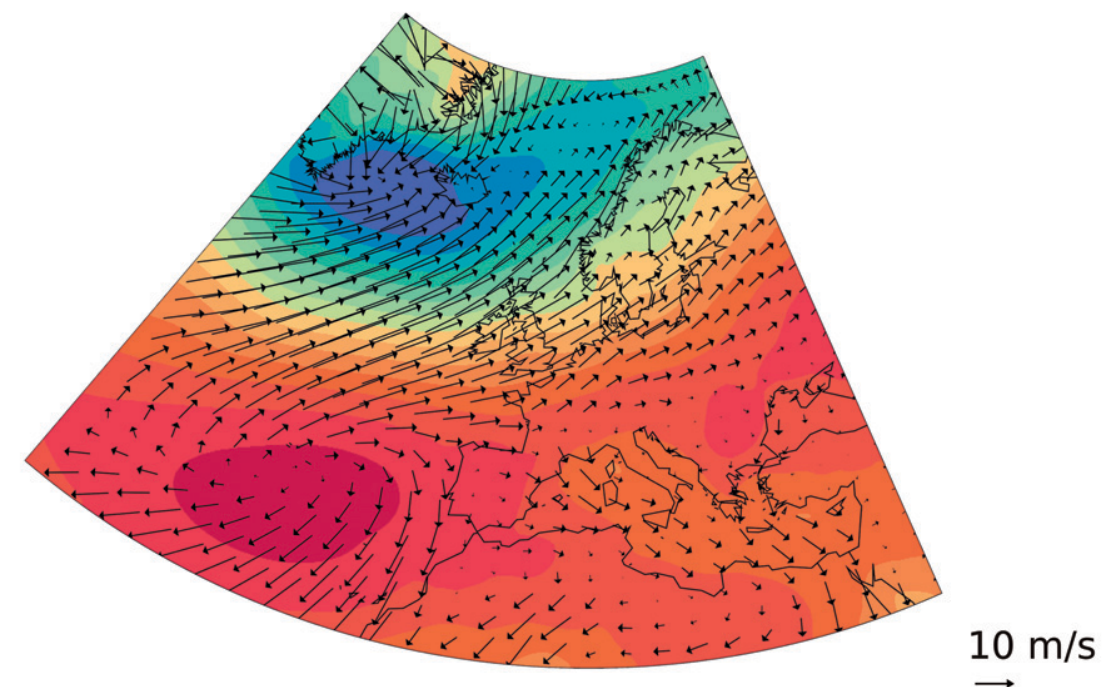

b) Winter (Oct.-to-Mar.), NAO-, SLP \& W10

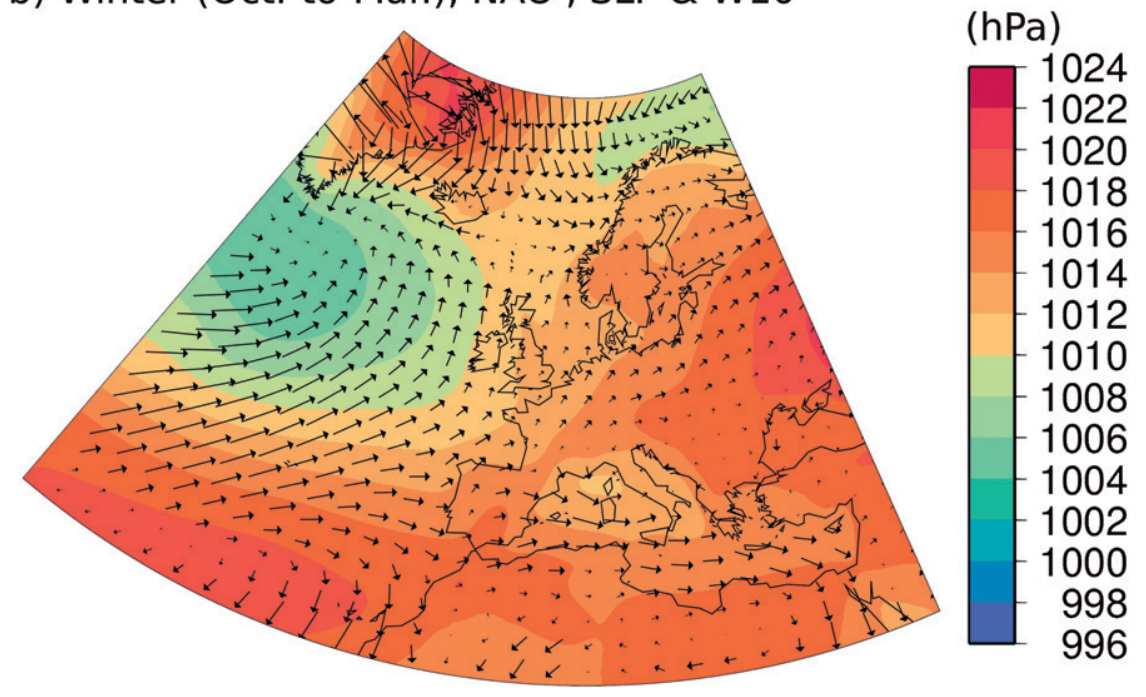

FIG. 1. Extended winter (October-March) climatology of sea level pressure (SLP by shaded colors; $\mathrm{hPa}$ ) and 10-m wind (W10; arrows) fields during (a) positive and (b) negative phases of $\mathrm{NAO}\left(\mathrm{NAO}^{+}>0.5\right.$ and $\mathrm{NAO}^{-}<-0.5$, respectively). Averaged period: $1959-2007$. Data for SLP and W10 were obtained from the ERA-40 reanalysis (Uppala et al. 2005) for the period 1959-2002 and from the ECMWF analysis for the period 2003-07. Data for the NAO index were obtained from the NOAA/CPC.

results obtained were conciliated with available measures of real hydropower, wind, and solar power generation. The relevance of these results, given the high economic cost of the energetic dependence of the IP, should positively affect future management decisions and energy strategies.

Section 2 describes the data and the methodology employed. Section 3 presents and discusses the assessment of the impact of the NAO on renewable energy resources and production. Section 4 summarizes the main contributions of this work.

\section{Data and methods}

In order to understand the primary underlying mechanisms through which the renewable energy production in the IP is affected by the NAO mode, its influence (i.e., the NAO impact) on the related meteorological variables (wind, precipitation, and surface solar radiation) is analyzed. The meteorological fields are obtained from a hindcast regional climate simulation that covers the whole IP with a spatial resolution of $10 \mathrm{~km}$ and that spans the period 1959-2007 having hourly temporal 
TABLE 2. Total number of positive and negative NAO events (identified from the detrended NAO series) throughout the study period for each month.

\begin{tabular}{lcccccccccccc}
\hline \hline & Jan & Feb & Mar & Apr & May & Jun & Jul & Aug & Sep & Oct & Nov & Dec \\
\hline NAO $^{+}$ & 20 & 21 & 18 & 17 & 13 & 16 & 13 & 16 & 17 & 18 & 11 \\
NAO $^{-}$ & 17 & 20 & 15 & 17 & 15 & 14 & 13 & 14 & 15 & 15 & 14 & 16 \\
\hline
\end{tabular}

resolution (appendix A). The characteristics of this database, namely its length and resolution, support its uniqueness to the best of our knowledge. Its reliability is rooted on 1) the well-established ability of the regional model used [the fifth-generation Pennsylvania State University-National Center for Atmospheric Research Mesoscale Model (MM5); Grell et al. 1994] to simulate regional circulations and reproduce observed climatologies (Kanamitsu et al. 2002; Gomez-Navarro et al. $2011) ; 2)$ the spatial resolution employed $(10 \mathrm{~km})$, which guarantees a proper representation of the regional features that greatly influence the atmospheric forecasts (i.e., orography and land use; Jimenez et al. 2006; Hughes et al. 2009); and 3) the reliance of the driven conditions used (reanalysis data), which can be considered "perfect" inputs for these kinds of runs (Christensen et al. 1997; Salzmann et al. 2007). Some results supporting the accuracy of this database are provided in appendix A.

Direct MM5 outputs were considered: wind speed and direction (SPD and DIR, respectively) at different vertical levels (10-m height, i.e., SPD10 and DIR10; and $0.9975,0.9925,0.9875$, and 0.9825 sigma levels); total precipitation (PRE), which is simply the sum of the convective and nonconvective precipitation forecast by MM5; surface downward shortwave radiation (SWD); and column-integrated cloud water (CLW) as a measure of cloudiness. The analysis is made at the monthly timescale for each month separately. Note that the length of the simulated series (we have 49 records in each monthly series, 1 per year) allows us to adopt a climatic perspective to characterize the NAO impact, instead of focusing on a few number of events, and enables a quite robust statistical treatment of the data. Since the focus of this study is on the high-frequency interannual variability of the NAO impact on the Iberian resources, the long-term trends in the series were removed before carrying out any calculation.

The monthly values of the NAO index for the simulated period were obtained from the National Oceanic and Atmospheric Administration/Climate Prediction Center (NOAA/CPC; www.cpc.ncep.noaa.gov). Following a common approach (e.g. Trigo et al. 2002), we have defined, using the detrended monthly series of the NAO index, classes of positive and negative phases of NAO $\left(\mathrm{NAO}^{+}>0.5\right.$ and $\mathrm{NAO}^{-}<-0.5$, respectively), with the remaining months corresponding to the normal class. Table 2 summarizes the total number of $\mathrm{NAO}^{+}$and $\mathrm{NAO}^{-}$events for each month in the study period. Detrending the original NAO series ensures that both classes have a similar occurrence and neither the $\mathrm{NAO}^{+}$nor the $\mathrm{NAO}^{-}$phase prevails at the beginning or end of the period.

The assessment of the influence of the NAO on wind, precipitation, and solar radiation over the IP is then primarily addressed in two steps. First, we evaluate the role of the NAO mode in driving the interannual variability of the meteorological fields by computing the "correlation patterns." These patterns depict the temporal correlation (computed through the Pearson coefficient) between the detrended monthly series of the meteorological variables and the detrended monthly NAO series at each grid point of the domain. These correlation patterns are used in the second step to mask the areas where the driving role of the NAO is not significant. Second, we quantify the signature of the NAO through composites showing the difference between negative and positive phases of the NAO in the mean fields of the various meteorological variables assessed. The importance of these differences in comparison with the whole natural variability of the assessed magnitudes is considered through the signal-to-noise ratio. This is the ratio between the absolute value of the $\mathrm{NAO}^{-}$and $\mathrm{NAO}+$ differences and the standard deviation of the corresponding temporal series. Whether the signal-tonoise ratio is above or below 0.75 is highlighted in the corresponding figures below. This threshold is achieved when the NAO impact exceeds $75 \%$ of the standard deviation of the series and was chosen because the majority of the obtained differences meet that condition. Additionally, we have also explored the NAO impact on the standard deviation of the meteorological series, as a measure of the uncertainty in the response to the NAO phase, as it has been found out, in particular, the asymmetry of the NAO impact on precipitation in an elongated strip between the Azores and southeastern Europe (Pires and Perdigão 2007). In all cases, the statistical significance of the results is evaluated through the application of two-tailed $t$ tests for the null hypothesis of equal means or zero correlation, respectively, and two-tailed $f$ tests for the null hypothesis of equal standard deviations, with significance level $p<0.10$ (Snedecor and 
Cochran 1989). Following this methodology, the signals obtained in summer were almost negligible and we decided to restrict this report to the October-March months for the sake of brevity.

The role of the NAO on the primary resources for HP has been further investigated using measured data from water storage and release within the main Iberian river basins. Water releases by dams are directly related to the water used by HP plants to produce electricity, while the water stored in the reservoirs (hereafter reservoir storage) informs us about the potential HP generation. Monthly data were provided by the Spanish Centro de Estudios y Experimentación de Obras Públicas (CEDEX; http://www.cedex.es/). In the analysis we only included the series without observational gaps covering the period between 1950 and 2007. We obtained series for each main river basin in Spain, based upon six reservoirs in the case of the Tagus basin, three for the Guadiana basin, nine series for the Guadalquivir basin, four series for the Segura basin, five series for the Júcar basin, and eight series for the Ebro basin (the locations of these basins can be seen in Fig. A1). Quantification of the influence of the NAO on reservoir storage and releases was done following a similar but not identical approach to that used for investigating the NAO impact on the meteorological variables. In this case, average reservoir storage and releases for positive and negative phases of the winter [December-March (DJFM) averages] NAO were calculated for each month of the year. Commonly, the NAO not only determines the availability of water resources during the winter months, but also of water storage amounts for subsequent months as well, given the lagged effects of precipitation on runoff and streamflow (Lorenzo-Lacruz et al. 2012).

Finally, correlations between the NAO index and the real WP, HP and SP generation data were investigated. These electricity generation data are regularly provided by the National Spanish Electric network (Red Eléctrica Española, REE; http://www.ree.es/) in annual or monthly reports and consist of aggregated data for the whole Spanish territory of the IP, leaving out Portugal. Monthly WP generation data are available for the period 2003-11, extending back until 1996 at the annual scale. The SP generation data are only available from 2005 (when the SP technology started to develop in Spain) to 2011 and consist only of annual values. The HP generation data considered here are annual values that span from 1940 to 2005. These electricity production data were normalized by the corresponding values of installed power before the calculus of correlations. Although the capacity factor of these installations may have changed significantly during the assessed period (Echavarria et al. 2008), these normalized values of power generation are the only source of power generation variability related to weather and climate conditions that we have at our disposal. However, the former issue, partially due to the more frequent mechanical outages at the earliest stages of the installations, should be borne in mind as it could introduce a non-natural variability factor into the series of normalized power generation that may mask the sought signature of the NAO.

\section{Results and discussion}

\section{a. Impacts of NAO on the wind field and WP generation}

\section{1) IMPACTS OF NAO ON THE WIND FIELD}

Figure 2 shows the $\mathrm{NAO}^{-}$minus $\mathrm{NAO}^{+}$composites for SPD at 10-m height above the sea level (SPD10), including the surrounding offshore areas since they are potentially relevant for WP. All of the represented values are statistically significant (with $p<0.10$ ) and supported by significant temporal correlations between the NAO and the SPD10 series ranging between 0.5 and 0.8 , mostly negative (not shown). Obtained results reveal an overall intensification in SPD10 in the months with negative NAO. Some exceptions exhibiting negative $\mathrm{NAO}^{-}$minus $\mathrm{NAO}^{+}$differences in SPD10 can be identified though, namely in northwestern areas in December and around the Strait of Gibraltar in March. Differences in SPD10 between opposite NAO phases reach $1.4 \mathrm{~m} \mathrm{~s}^{-1}$ over land areas, being stronger offshore, with the signal-to-noise ratio sustained above 0.75 in most cases. These values represent variations of about $10 \%-20 \%$ in the resource (below $10 \%$ offshore though), being maximum in December, February, and March. The spatial distribution of the differences is largely dependent on the month. In October, the NAO impact is concentrated mainly over northern and western areas; in November and March, it is found over northern and southeastern areas; in December and January, it is more pronounced westward again, more in the south than in the north; and it is quite widespread in February.

It is worth mentioning that the standard deviation of the SPD10 series is not significantly affected by the NAO phase: it does not change notably when considering only months with negative or positive NAO. This point is important because, statistically, the degree of determinism imposed by the NAO mode on the predictand (i.e., the wind speed in this case) would decrease with larger standard deviations. Therefore, the overall gain that can be drawn from negative NAO phases in terms of mean SPD10 values (hence, in terms of WP) in comparison with the positive NAO phases is not 
a) October, NAO-impact, SPD10

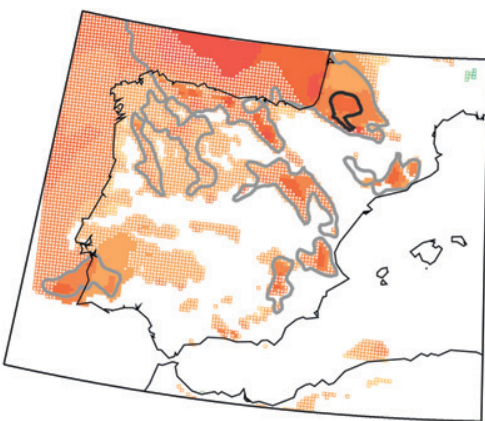

d) January, NAO-impact, SPD10

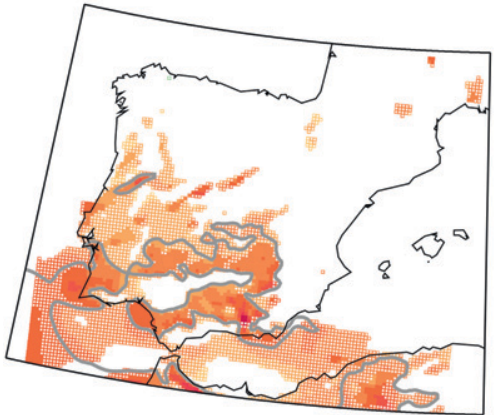

b) November, NAO-impact, SPD10

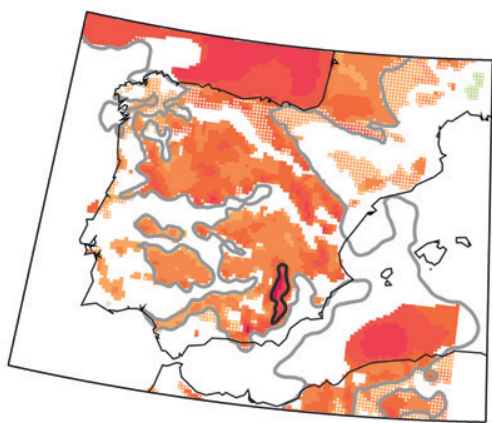

e) February, NAO-impact, SPD10

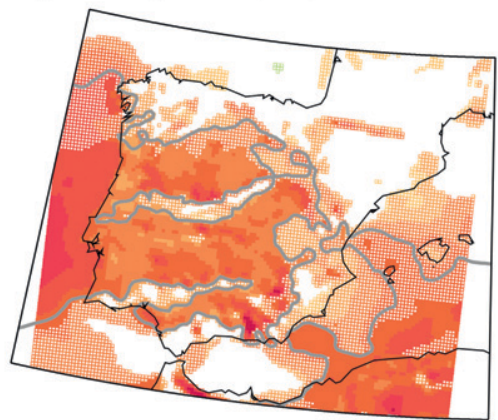

c) December, NAO-impact, SPD10

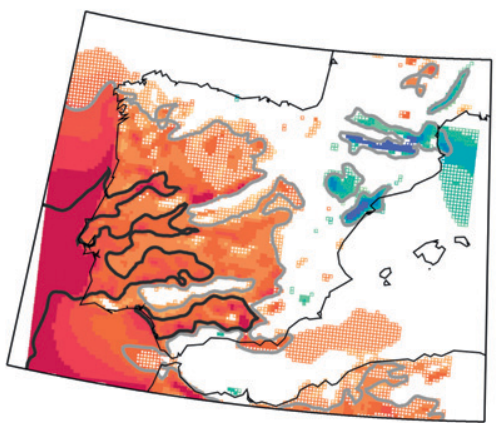

f) March, NAO-impact, SPD10

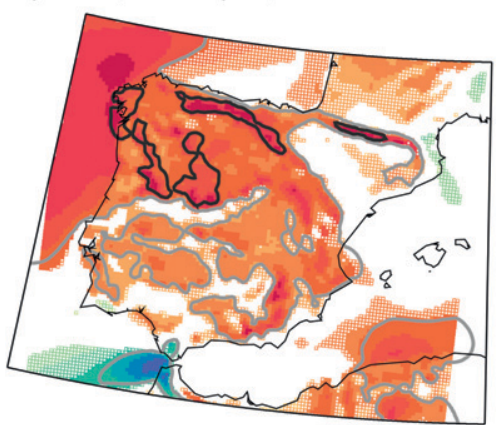

$(\mathrm{m} / \mathrm{s})$

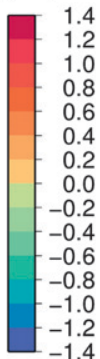

(\%)

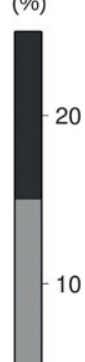

FIG. 2. NAO impact on SPD10: differences in mean SPD10 $\left(\mathrm{m} \mathrm{s}^{-1}\right)$ between negative and positive phases of NAO, statistically significant at the $10 \%$ level and supported by significant temporal correlations between the SPD10 and NAO series. Gray-shaded contours depict the differences expressed as a percentage. The superimposed white dots indicate a signal-to-noise ratio that is below 0.75 .

misleading from the point of view of its potential predictability (Palutikof et al. 1987).

The NAO impact on SPD10 can be fairly well understood by considering the NAO impact on the wind direction. This was anticipated in Fig. 1, but can be better recognized in Fig. 3. In Fig. 3, exploiting the full resolution of our hindcast database, we can observe with a high level of detail the NAO impact on DIR10 over some of the areas showing the strongest and most striking responses in Fig. 2. We have selected the cases of December and March, which show the characteristic fingerprint but also some unusual features.

Figures $3 \mathrm{a}$ and $3 \mathrm{c}$ focus on areas with positive $\mathrm{NAO}^{-}$ minus $\mathrm{NAO}^{+}$differences in SPD10, which is related to the intensification of the westerly and southwesterly winds during $\mathrm{NAO}^{-}$. Since the main river basins and the main mountain systems in western Iberia run predominantly east-west or northeast-southwest (Fig. A1), such a westerly and southwesterly flow is optimally channeled by the orography (Figs. 3a,c, left). On the contrary, the northwesterly winds promoted by $\mathrm{NAO}^{+}$ find in the IP orography great barriers to its advancement (Figs. 3a,c, right). Indeed, the largest positive $\mathrm{NAO}^{-}$minus $\mathrm{NAO}^{+}$differences in SPD10 appear in 1) the lowlands and within/around the river basins (e.g., Fig. 2c), since this effect is less noticeable at the tops of the mountains where there is no preferred direction; 2) the southern face of the northern mountain systems (e.g., Fig. 2f), since these systems (running east-west near the coast) stop the northerly $\mathrm{NAO}^{+}$-related flow; and 3 ) the west side of the Penibetic System in southern Spain (e.g., Fig. 2b), where the more windy conditions during $\mathrm{NAO}^{-}$may respond to the channeling of the associated westerly flow along the Guadalquivir River basin.

The two areas showing opposite responses to the $\mathrm{NAO}$ mode (i.e., negative $\mathrm{NAO}^{-}$minus $\mathrm{NAO}^{+}$differences in SPD10) are also included in Fig. 3. Figure 3b focuses on the $\mathrm{NAO}^{+}$enhancement of the wind blowing down the Ebro river valley (i.e., the cierzo wind) in December, which is promoted by the channeling of the northwesterly flow associated with $\mathrm{NAO}^{+}$(Martín et al. 2010). Actually, it can be seen in Fig. 2c that the largest differences in wind speed in that area/month do not appear inside the valley, where in both cases $\left(\mathrm{NAO}^{+}\right.$ and $\mathrm{NAO}^{-}$phases) the wind is strongly driven by the orography, but in the surrounding areas, where the orographic wind channeling is less pronounced. It could happen that if the incoming air blows in a direction at odds with that imposed by the orography (as happens during $\mathrm{NAO}^{-}$), the shear effect with the air blowing down-valley could weaken the wind speed. On the contrary, during $\mathrm{NAO}^{+}$, the wind direction is the same 
a) December, NAO-impact, DIR10 (South-West)

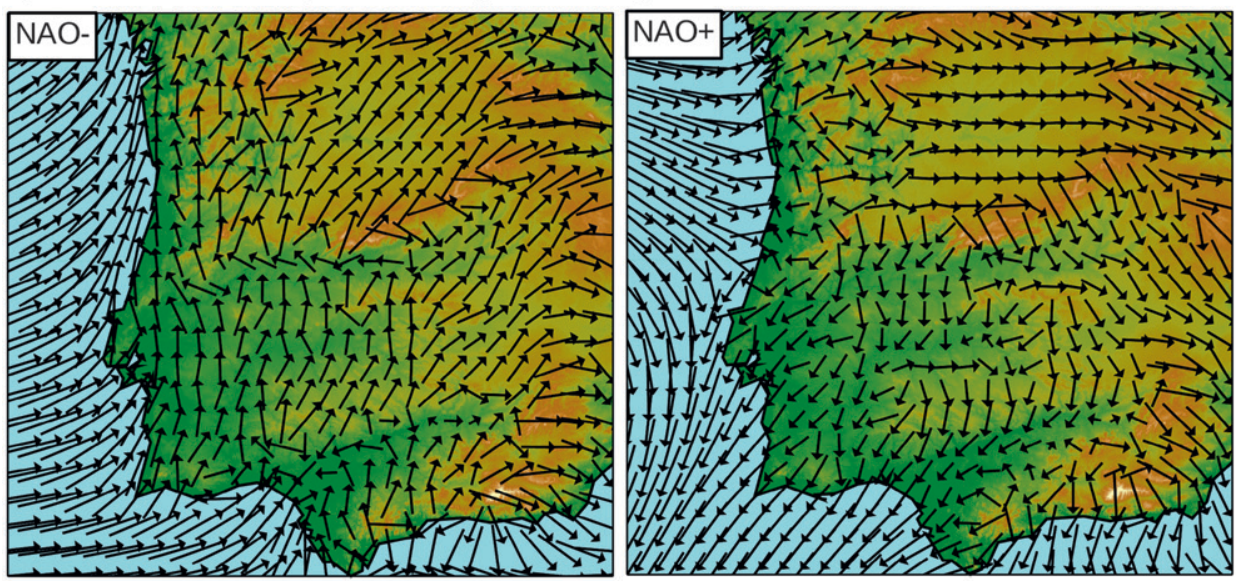

b) December, NAO-impact, DIR10 (North-East)
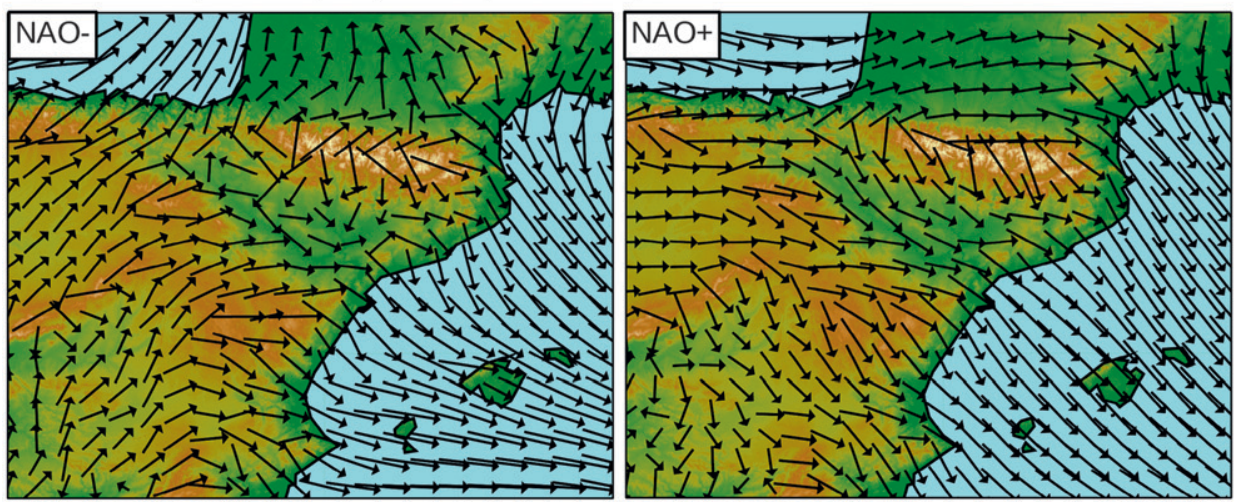

c) March, NAO-impact, DIR10 (North-West)
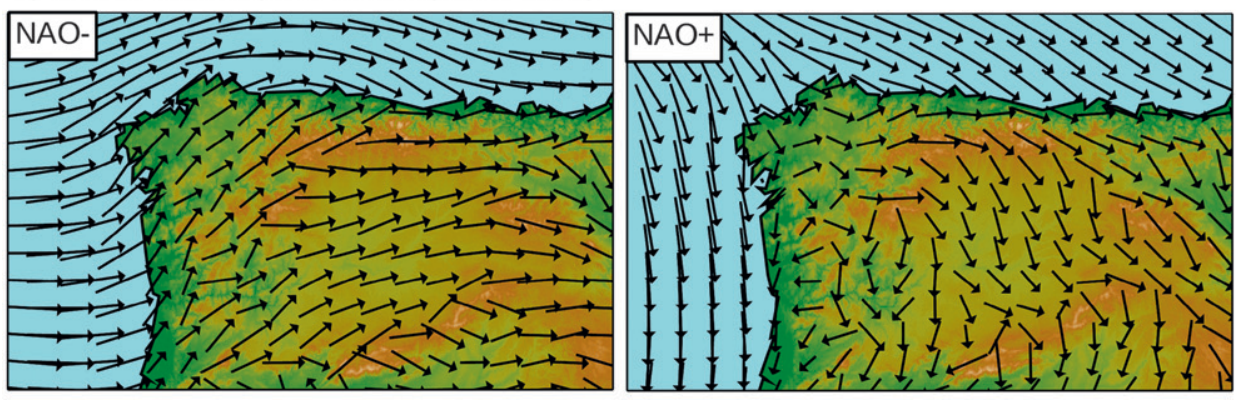

d) March, NAO-impact, DIR10 (South)
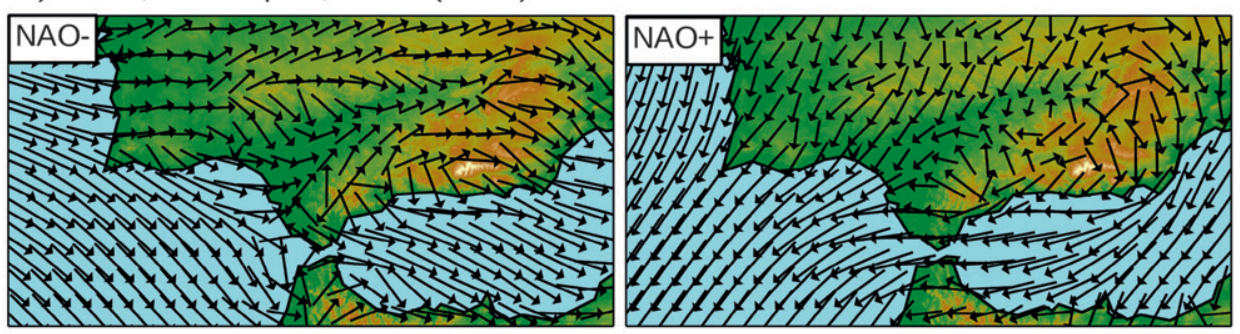

(Length scale for arrows: $10 \mathrm{~m} / \mathrm{s} \equiv \longrightarrow$ )

FIG. 3. Mean wind field during (left) negative and (right) positive phases of NAO in (a),(b) December and (c),(d) March over different areas. Note that, although the NAO impact on wind speed is specifically depicted in Fig. 2, here the length of the arrows is also proportional to the mean wind speed in each NAO phase. The topography, as seen by the model, is depicted by shaded colors, as in Fig. A1, described below. 
TABLE 3. Spatial correlation between the patterns of the NAO impact on the wind speed at different vertical levels and the patterns of the NAO impact on SPD10 (shown in Fig. 2). The vertical levels are $\sigma$ levels at $0.9975(\sigma 1), 0.9925(\sigma 2), 0.9875(\sigma 3)$, and $0.9825(\sigma 4)$, which corresponds to the range of heights $(\mathrm{m})$ over the entire IP that is indicated in the first column (in parentheses).

\begin{tabular}{lcccccc}
\hline \hline & Oct & Nov & Dec & Jan & Feb & Mar \\
\hline$\sigma 1(16-18 \mathrm{~m})$ & 1.00 & 1.00 & 1.00 & 1.00 & 1.00 & 1.00 \\
$\sigma 2(50-55 \mathrm{~m})$ & 0.98 & 0.95 & 0.98 & 0.98 & 0.98 & 0.99 \\
$\sigma 3(80-90 \mathrm{~m})$ & 0.95 & 0.89 & 0.96 & 0.96 & 0.95 & 0.98 \\
$\sigma 4(115-130 \mathrm{~m})$ & 0.93 & 0.84 & 0.94 & 0.94 & 0.93 & 0.97 \\
\hline
\end{tabular}

in the center of the valley and in the surrounding areas, without such a shear effect thereby lowering the wind speed as we move away from the center of the valley. In the case of the areas surrounding the Strait of Gibraltar in March (Fig. 3d), the wind blows from the west during $\mathrm{NAO}^{-}$and from the east during $\mathrm{NAO}^{+}$(i.e., the levanter wind). In the second case, the mountains on both sides of the strait (Spanish and Moroccan) act as a funnel (orographic blocking), which induces the wind near the surface to blow faster as it passes through the strait (Dorman et al. 1995). This effect does not take place when the air arrives from the west or the northwest (as it happens during $\mathrm{NAO}^{-}$), since the orographic configuration that westerly winds find in the Strait of Gibraltar does not promote a clear channeling.

Finally, given the tendency to place the commercial wind turbines as high up as possible (where it is windiest), we felt it necessary to assess how the impact of the NAO on SPD evolves as the altitude increases. To limit the number of figures to a reasonable number, we adopted a more condensed approach here. Table 3 shows the values of the spatial correlation between the patterns of the NAO impact on SPD at the various sigma $(\sigma)$ levels (their heights are specified in the table) and those corresponding to the SPD10 shown in Fig. 2. Almost all of these correlations are over 0.95 , even for the highest level $\sigma 4$, whose height in meters above the sea level ranges from 115 to $130 \mathrm{~m}$ through the entire IP domain. This means that the spatial distribution of the NAO-impact patterns remains nearly constant as height increases. However, Fig. 4a, showing the spatially averaged NAO impact on the wind speed at the different vertical $\sigma$ levels, reveals a progressive increment with height of the NAO impact on the wind speed. This novel finding further emphasizes the long-term structural role played by the NAO mode when one considers the interannual variability of the wind resource.

Because of the nonlinearity between wind speed and wind power, the former NAO impact on the wind resource cannot be directly interpreted in terms of wind

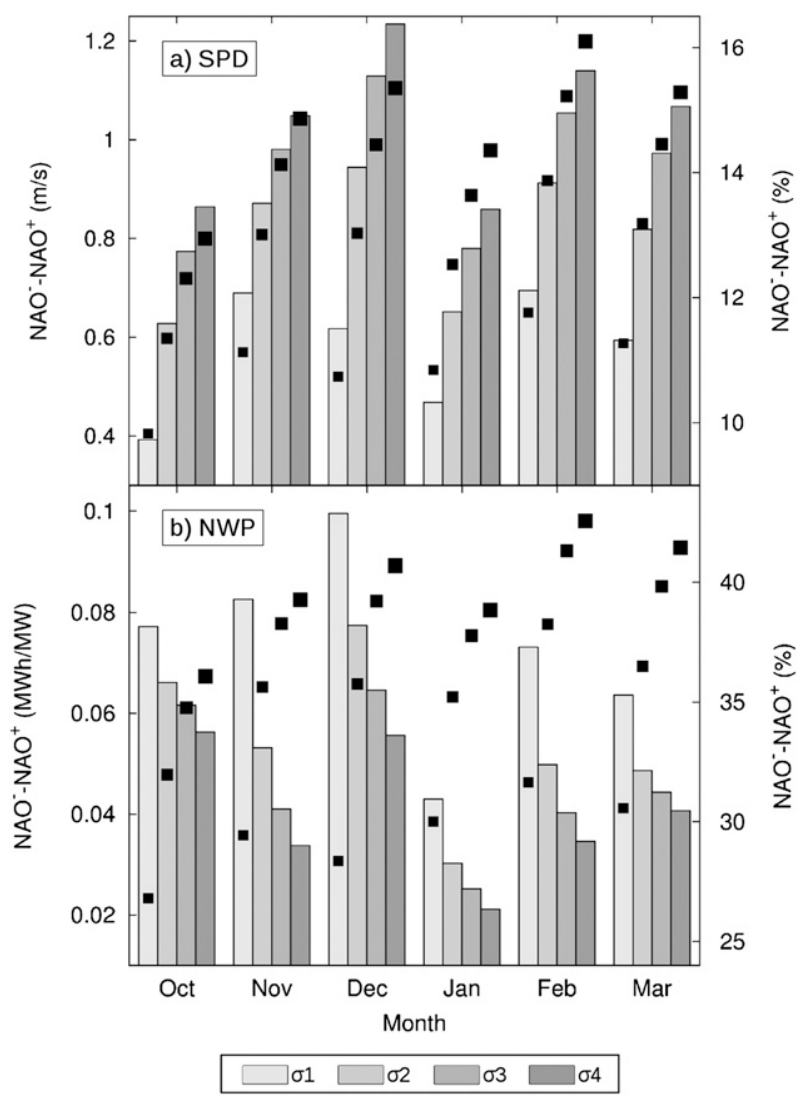

FIG. 4. Spatial averages of the NAO impact on (a) SPD and (b) normalized WP generation (estimated as explained in the text) at the vertical levels $\sigma 1, \sigma 2, \sigma 3$, and $\sigma 4$ (see heights in Table 3 ). The spatial averages involve only the grid points with statistically significant $(p<0.10)$ and positive $\mathrm{NAO}^{-}-\mathrm{NAO}^{+}$differences in SPD. Squares represent the $\mathrm{NAO}^{-}-\mathrm{NAO}^{+}$difference in SPD $\left(\mathrm{m} \mathrm{s}^{-1}\right)$ and in normalized WP generation $\left(\mathrm{MWh} \mathrm{MW}^{-1}\right)$ (left $y$ axes). Gray-shaded bars show these differences as percentages (right $y$ axes).

power generation. Therefore, in order to provide some insight on the impact of the NAO on WP, Fig. 4b replicates Fig. 4a but is built on monthly mean series of estimated WP generation. These series were obtained following the specifications of Ruiz-Arias et al. (2012) for the turbine model G87 applied to the original hourly series of wind speed provided by the MM5 simulation. The resulting hourly series of estimated WP generation were then time averaged up to the monthly timescale and normalized by the nominal rated power generation of the turbine model considered. The results provided in Fig. 4b reveal that the impact of the NAO on WP still increases with height in absolute terms (squares in Fig. 4b). However, such an increase is less appreciable at the highest levels compared to near the surface, which actually leads to a decrease in NAO impact on WP in relative terms as we go to higher altitudes (bars in 
a) WPG \& WPI (annual data)

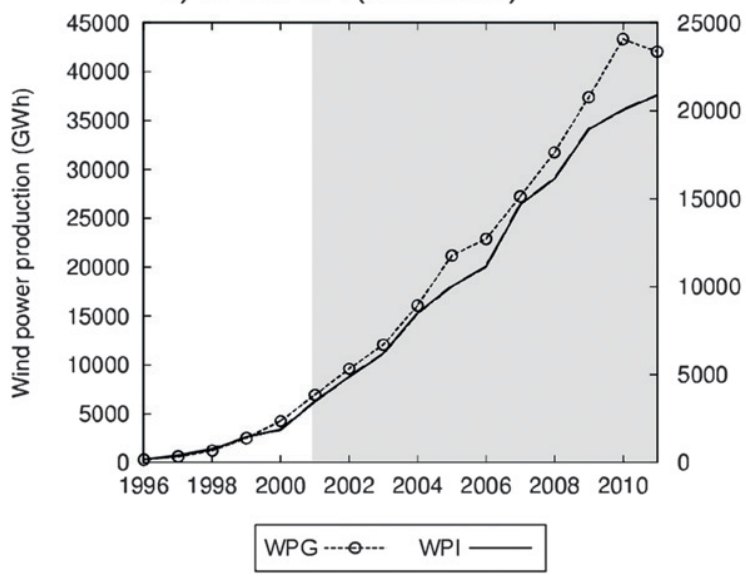

b) NWPG \& NAO (annual data)

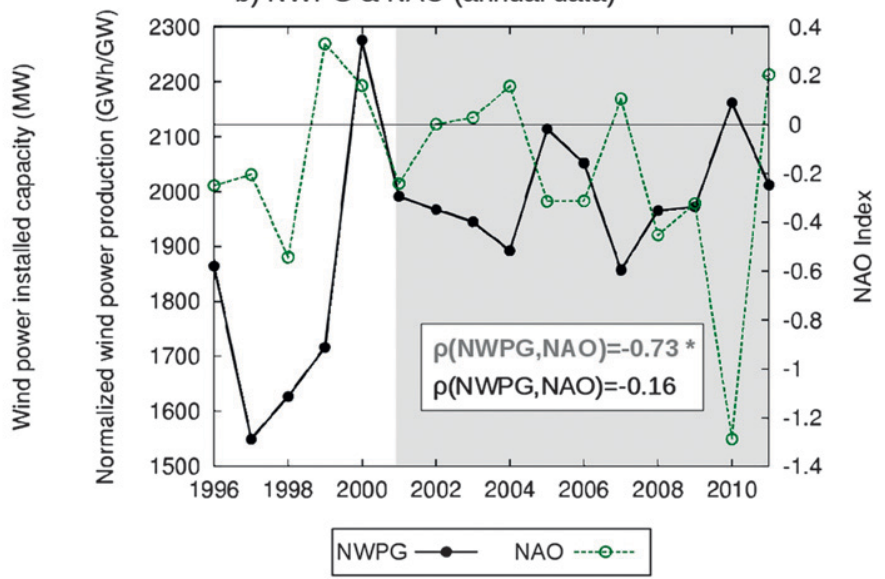

FIG. 5. Temporal series of annual values of (a) wind power generation (WPG; GWh) and wind power installed (WPI; MW) and (b) normalized wind power generation (i.e., the generation divided by the installed capacity) (NWPG; GW h GW ${ }^{-1}$ ) and NAO index. The $\rho(\mathrm{NWPG}, \mathrm{NAO})$ in $(\mathrm{b})$ is the temporal correlation between both of the series depicted, during the entire period (i.e., 1996-2011; in black) and after discarding the first $5 \mathrm{yr}$ (i.e., the gray-shaded period 2004-11; in gray). The asterisk indicates statistical significance $(p<0.1)$.

Fig. 4b). This may be due to the fact that the cut-in speed of the wind turbine should be easier to achieve at the highest levels regardless of the NAO phase, while the cutoff speed should be surpassed too often at the high levels during $\mathrm{NAO}^{-}$. Moreover, the $\mathrm{NAO}^{-}$minus $\mathrm{NAO}^{+}$differences, when expressed in relative terms, are divided by higher mean values of normalized WP in the top levels than at the near-surface levels. Nonetheless, even at the highest level considered, the differences between NAO phases in WP generation in relative terms are over $25 \%$.

\section{2) IMPACTS OF NAO ON WP GENERATION}

Based on real data, Fig. 5 depicts the evolution of the installed and generated WP in Spain for the period 1996-2011, and its relation to the NAO index, at the annual time scale. WP installations have unceasingly grown since the mid-1990s, with a corresponding increase in the WP generation (Fig. 5a). However, the normalized WP generation (i.e., the ratio between the WP generation and the installed capacity) shows strong interannual variations (Fig. 5b). To what extent does the NAO explain such variability? At this annual scale, the temporal correlation between the NAO and the normalized WP generation series shows a very weak value $(-0.16)$ when considering the entire measured period (1996-2011). However, this value grows considerably (to -0.73 ) after discarding the first $5 \mathrm{yr}$, that is, once an acceptable degree of maturity for the wind power technology and the corresponding installations can be assumed. Thus, even at the annual scale, the signature of the NAO on the real WP generation can be recognized. As a reference, the difference in the normalized WP generation between 2007 and 2010, the years with the highest and lowest values, respectively, of the annual NAO in the last few years, is about $15 \%$. We believe that the main reason for the poor correlation between NAO and WP at the beginning of the WP data period results from the fact that until the late 1990s most of the wind energy production was obtained from wind farms located in northwest and eastern areas, where the NAO signal on the WP is relatively weak (Fig. 2). Additionally, the problems found during the early stages of the WP installations, such as non-natural intermittent operation, could also be masking the NAO signal, as commented upon previously.

This analysis has also been performed on a monthly time scale for October-March during the period 200311 (Table 4), which yielded high significant correlations between the monthly series of normalized WP generation and NAO, except for the months of November and March. In December and January this correlation is above -0.6 , involving differences in the normalized WP generation between the highest-NAO year and the lowestNAO year of $20 \%-30 \%$. In October and February the correlation is above -0.8 and the differences are $60 \%-$ $80 \%$. These results are in fairly good agreement with those expected from the former MM5 simulation-based assessment.

\section{b. Impacts of $N A O$ on precipitation and $H P$ generation}

\section{1) IMPACTS OF NAO ON PRECIPITATION}

Precipitation is the main contribution to the water resources of the Iberian basins (snow plays a minor but 
TABLE 4. Temporal correlation between the monthly series of the NAO index and the normalized wind power generation series, $\rho$ (NWPG, NAO), and difference (\%) in the normalized WP generation between those years with the lowest and highest NAO values for those months showing significant values of $\rho$ (NWPG, NAO), which is highlighted in boldface. The normalized WP generation is computed from monthly values of WP generation but considering annual values of WP installed capacity, since monthly data of WP installed capacity were not available. Period considered is $2003-11$.

\begin{tabular}{lcc}
\hline \hline & $\rho(\mathrm{NWPG}, \mathrm{NAO})$ & $\mathrm{NAO}^{-}-\mathrm{NAO}^{+}$ \\
\hline Oct & $\mathbf{- 0 . 8 6}$ & 60 \\
Nov & -0.29 & \\
Dec & $\mathbf{- 0 . 6 5}$ & 30 \\
Jan & $-\mathbf{0 . 6 1}$ & 20 \\
Feb & $-\mathbf{0 . 8 3}$ & 85 \\
Mar & -0.34 & \\
\hline
\end{tabular}

relevant role in northern IP river basins bordered by high mountains) and, thus, the main primary resource for the related HP. Acknowledging that much work has been done previously on the impact of the NAO on precipitation at coarser resolutions (Zorita et al. 1992; Rodó et al. 1997; Esteban-Parra et al. 1998; Rodrigo et al. 2000; Trigo et al. 2002, 2008; Gallego et al. 2005), the signature of the NAO on the mean amount of precipitation at $10-\mathrm{km}$ resolution for the whole IP is presented in the composites of Fig. 6. These differences are supported by significant (negative) temporal correlations between the NAO and the precipitation series up to -0.7 (not shown). The largest signals appear over western, southern, and inner Iberia, with many areas presenting differences larger than $60 \mathrm{~mm}$ month $^{-1}$ (sometimes exceeding even $100 \mathrm{~mm}$ month $^{-1}$ ). These differences are largely above one standard deviation of the whole precipitation series, and represent variations of $50 \%$ and $100 \%$ in the resource between positive and negative NAO phases, even exceeding $200 \%$ in the southwestern IP during December. Overall, the spatiotemporal distribution of the $\mathrm{NAO}^{-}$minus $\mathrm{NAO}^{+}$differences in PRE (Fig. 6) appears to be very similar to the spatiotemporal distribution of the $\mathrm{NAO}^{-}$ minus $\mathrm{NAO}^{+}$differences in SPD10 previously described (Fig. 2). This indicates that the response of both variables (precipitation and wind) to the NAO mode should be closely related. Indeed, both responses may be actually rooted in the same feature, namely the role of the $\mathrm{NAO}^{-}\left(\mathrm{NAO}^{+}\right)$mode in favoring (reducing) the zonal circulation (i.e., the westerly winds advecting moist air from the ocean) and the storms penetrating into Iberia from the Atlantic (Ulbrich et al. 1999; Trigo et al. 2002; Paredes et al. 2006; Trigo 2006).

However, a different picture arises along the northern coast of the IP and north of the Pyrenees in December, a) October, NAO-impact, PRE

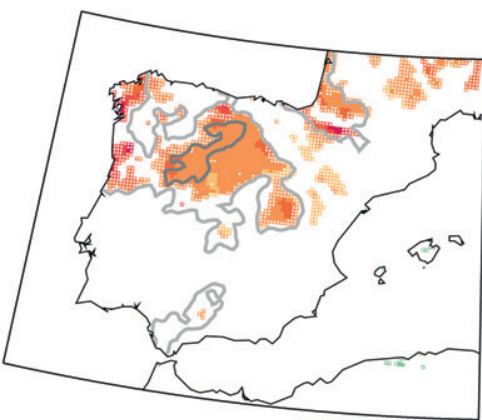

d) January, NAO-impact, PRE

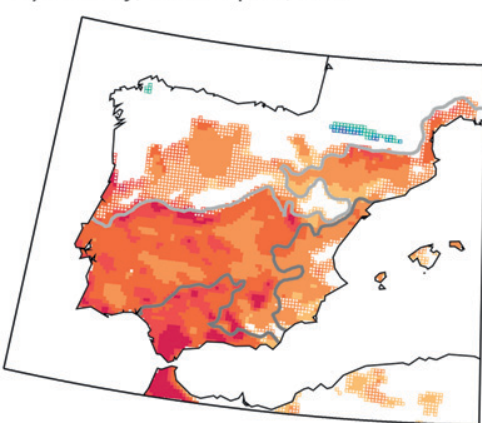

b) November, NAO-impact, PRE

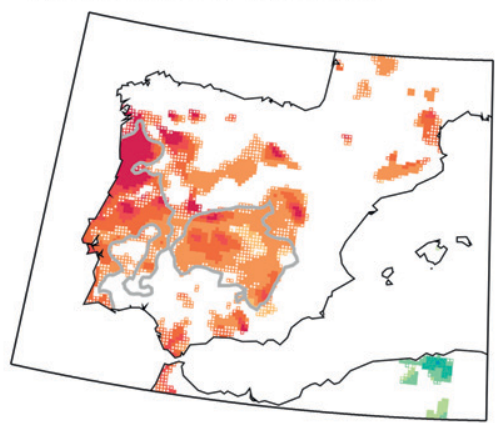

e) February, NAO-impact, PRE

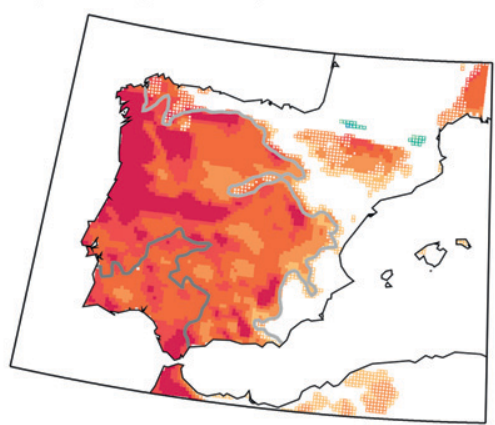

c) December, NAO-impact, PRE

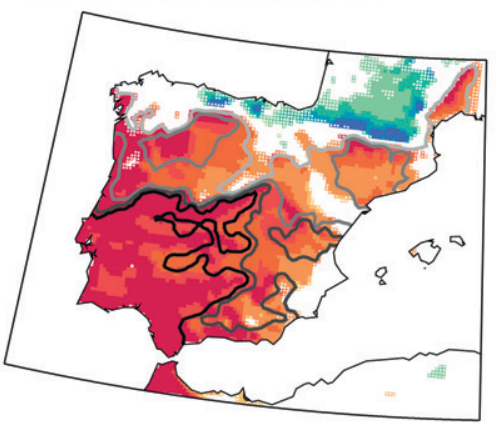

f) March, NAO-impact, PRE

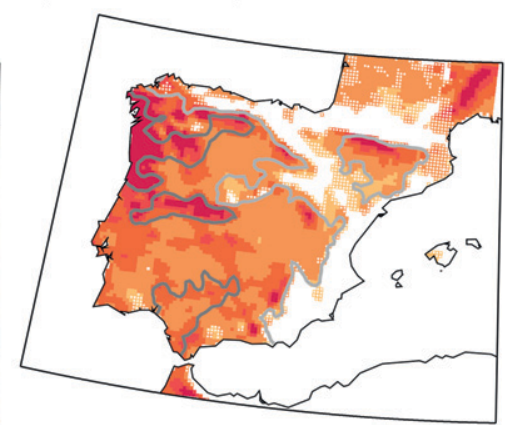

$(\mathrm{mm} / \mathrm{m})$

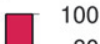

80 60 40 20 20 $-40$ $-60$ $-80$ $-100$

(\%) $-200$ 150 $-100$ 50

FIG. 6. As in Fig. 2, but for PRE (mm month ${ }^{-1}$ ). 
with enhanced precipitation during the positive phases of NAO (Fig. 6c). This exceptional behavior should respond to the fact that, whereas $\mathrm{NAO}^{+}$ promotes the westerly and northwesterly winds over these regions (Fig. 3b, right), thus enhancing the humidity advection from the ocean and, finally, precipitation, during $\mathrm{NAO}^{-}$, the mean flow is opposite, coming from inland to the water masses (Fig. 3b, left). In fact, the barrier effect of the Cantabrian mountain system and the Pyrenees interrupting, south of them, such a $\mathrm{NAO}^{+}$-promoted enhanced precipitation pattern can be appreciated as the contrasting behavior is highly constrained to the north face of the mountainous strip.

Nevertheless, it should be stressed that, in general, $\mathrm{NAO}^{-}$not only induces higher values of mean precipitation but also enlarges the standard deviation of the precipitation series (sdev). The patterns of the NAO impact on PREsdev display significant positive $\mathrm{NAO}^{-}$ minus $\mathrm{NAO}^{+}$differences during all the considered winter months over the areas where $\mathrm{NAO}^{-}$was found to enhance the mean precipitation (not shown). In most of the cases, the interannual variability of the PRE series is more than double for the $\mathrm{NAO}^{-}$class months compared to the $\mathrm{NAO}^{+}$class months. Therefore, the positive shift in mean PRE during $\mathrm{NAO}^{-}$in those areas is accompanied by a widening of the corresponding probability density function of PRE, with some impact in the probability of occurrence of extreme rainfall, as was similarly highlighted for southern Iberia by Muñoz-Díaz and Rodrigo (2003). Hence, although $\mathrm{NAO}^{-}$could be thought to have a positive impact in terms of HP by enlarging the mean amount of precipitation, it also introduces higher interannual variability, which is not desirable for management decision making.

\section{2) IMPACTS OF NAO ON HP GENERATION}

One should expect that the impact of the NAO on precipitation should be reflected in the corresponding river flow [which has been established elsewhere; e.g., Trigo et al. (2004), López-Moreno et al. (2007), MoránTejeda et al. (2011), and Trigo (2011)] and, finally, on HP generation. In particular, a previous analysis of the influence of the NAO on 187 streamflow series that are widespread across the IP showed a significant influence, particularly in the Atlantic watershed (Lorenzo-Lacruz et al. 2011). Also, persistence of the winter NAO conditions throughout the year was observed, mainly in highly regulated basins. Hence, this section is devoted to deepening our previous knowledge by focusing on other hydrological parameters with a more direct impact on hydroelectric production, namely, reservoir water storage and releases.

Figure 7 summarizes the water stored for each month of the year in the selected reservoirs of six major basins within the IP for years with winter (DJFM averaged) $\mathrm{NAO}^{+}$and $\mathrm{NAO}^{-}$. This quantity shows a high degree of seasonality, being usually higher during late winter and spring (except for the Ebro basin, where the storage peak moves toward the beginning of the summer as a consequence of the snow melting processes in the Pyrenean tributaries). There are, however, clear differences in the reservoir storage during the different months for the $\mathrm{NAO}^{+}$and $\mathrm{NAO}^{-}$class years, with the winter NAO impact propagating throughout the year in most of the basins. The greatest differences between NAO phases were observed in the basins belonging to the Atlantic watershed (Tagus, Guadiana, and Guadalquivir), but also in the Mediterranean Segura basin, which depends on the water transferred from the headwaters of the Tagus River (Lorenzo-Lacruz et al. 2010). It is noteworthy that significant differences are observed along the whole year in the southernmost basins (Guadalquivir and Segura).

Figure 8 shows the average water released for the same basins. The $\mathrm{NAO}^{+}$episodes are generally related to low releases (with low variability regarding the longterm average), except in the Segura basin where the dry conditions associated with $\mathrm{NAO}^{+}$phases are counteracted by releasing the water transferred from the Tagus basin during the summer. On the other hand, the $\mathrm{NAO}^{-}$ years show high releases during winter (especially for February) in the basins belonging to the Atlantic watershed, whereas during the rest of the year the differences between $\mathrm{NAO}^{+}$and $\mathrm{NAO}^{-}$are small. Given that reservoirs are managed to synchronize water availability with water demand by adjusting the water release as a function of the river inflow to the reservoir and the desired storage volume, these results are explained as follows. For $\mathrm{NAO}^{-}$, there is a significant winter peak in the inflow to the reservoirs and thus the largest releases take place during that season. In contrast, during $\mathrm{NAO}^{+}$ the input in winter is not as strong. Thus, the water released by dams is reduced to increase the water storage as much as possible in order to guarantee the supply in summer. This argument also explains that significant differences between $\mathrm{NAO}^{+}$and $\mathrm{NAO}^{-}$are more clearly observed in the reservoir releases than in the reservoir storage, since these releases are regulated through the water management strategy.

The analysis of the NAO impact on reservoir storage and releases anticipates the important NAO impact on HP generation, which is confirmed by the results presented in Fig. 9. The installed HP capacity has 

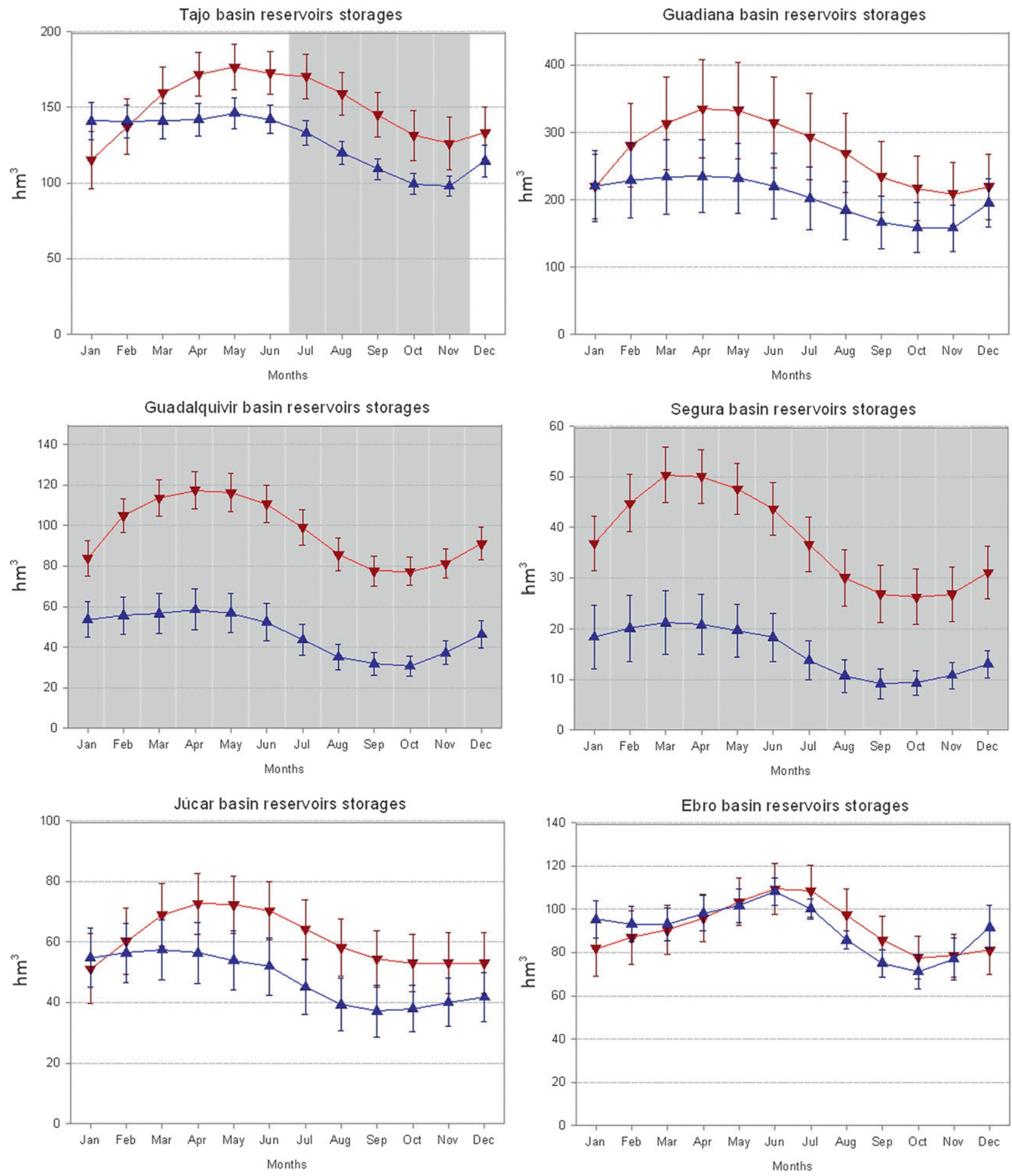

FIG. 7. Average reservoir storage $\left(\mathrm{hm}^{3}\right)$ for $\mathrm{NAO}^{+}$(blue) and $\mathrm{NAO}^{-}$(red) years in six different Iberian basins (DJFM-averaged NAO values are considered for the classification of the years). Triangles represent the mean storage, and whiskers represent the mean's standard deviation. Significant differences $(p<0.10)$ between $\mathrm{NAO}^{+}$and $\mathrm{NAO}^{-}$are gray shaded. 

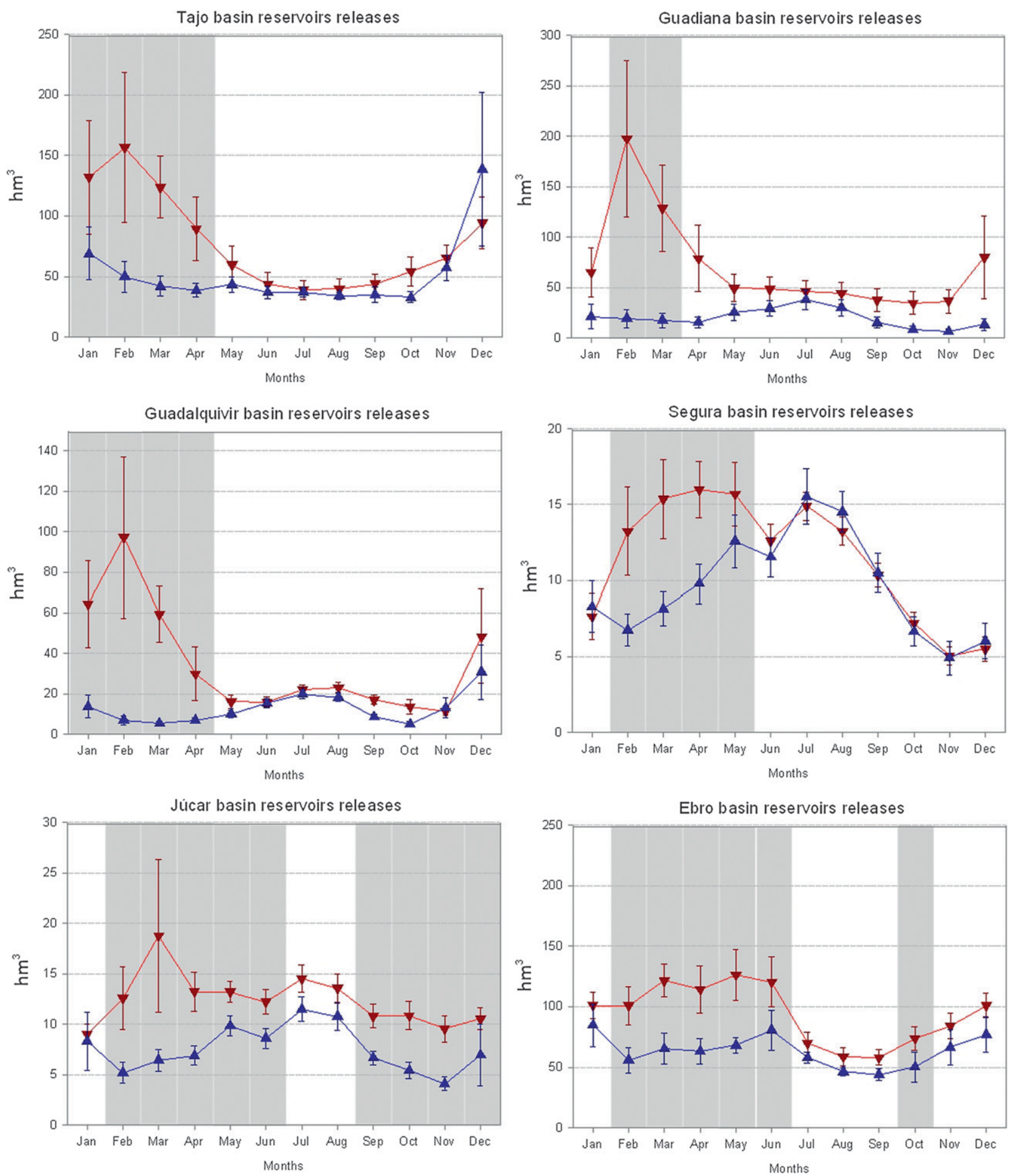

FIG. 8. As in Fig. 7, but for reservoir releases $\left(\mathrm{hm}^{3}\right)$.

noticeably increased in Spain since 1940 with a corresponding increase in HP generation, but the normalized annual HP generation is significantly correlated with the winter NAO variability $(-0.5)$. In particular, it can be observed that the large increase in the winter NAO values between the 1960s and 1990s coincides with a decline in the annual normalized HP generation. 

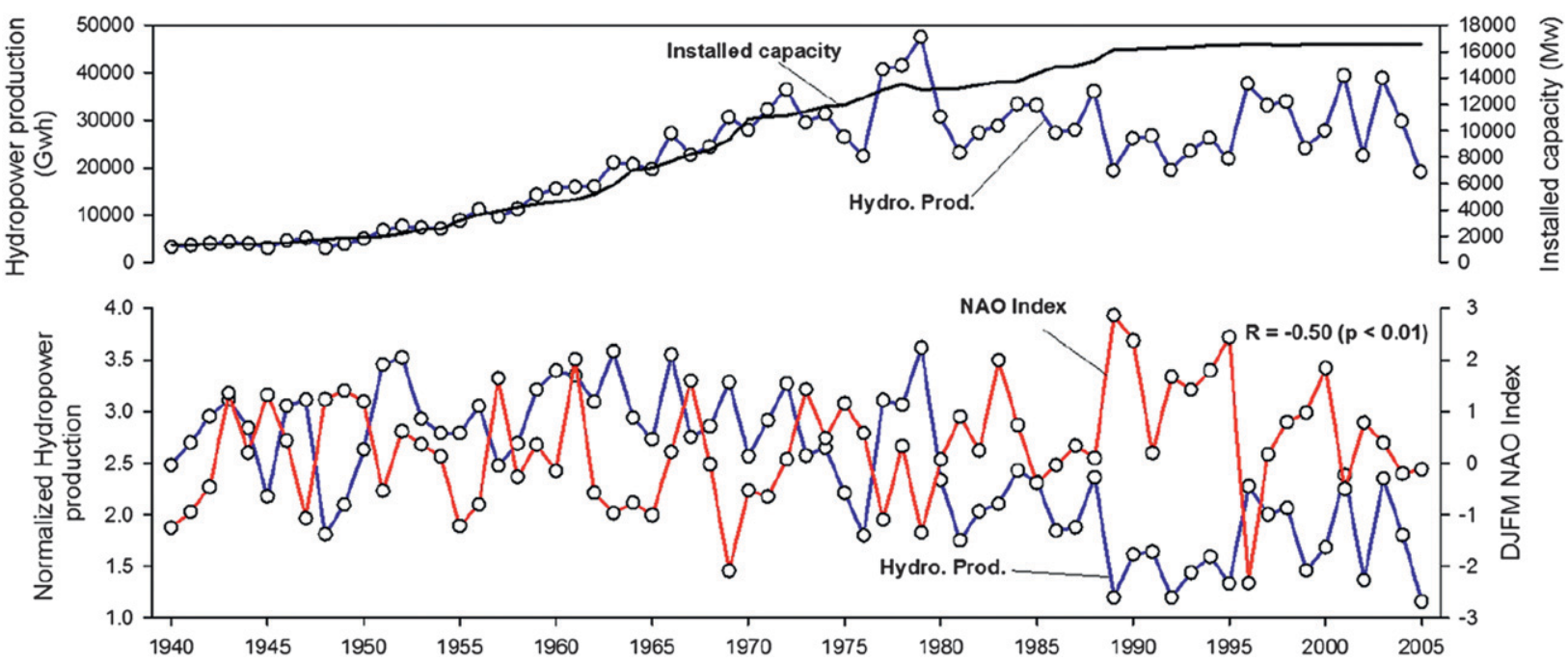

FIG. 9. (top) Evolution of annual hydropower power generation (blue; GWh) in Spain and the total hydropower power installed capacity (black; MW). (bottom) Evolution of the normalized hydropower power generation (i.e., the annual hydropower power generation divided by the installed capacity) (blue; $\mathrm{GW} \mathrm{h} \mathrm{MW}^{-1}$ ) and the winter NAO index (red). The correlation coefficient $R$ between both series is also shown.

\section{c. Impacts of $N A O$ on surface solar radiation and SP generation}

\section{1) IMPACTS OF NAO ON SURFACE SOLAR RADIATION}

Few previous research efforts have dealt explicitly with the NAO impact on solar resources when compared with the corresponding work analyzing the impact on hydropower or even the wind resource. Nonetheless, these studies provide enough evidence that NAO does indeed affect cloudiness and, thus, the solar radiation reaching the surface, over Europe (Pozo-Vázquez et al. 2004; Sanchez-Lorenzo et al. 2008; Chiacchio and Wild 2010; Pozo-Vázquez et al. 2011). However, these studies have either focused on "long term" decadal trends, without accounting for the "high frequency" interannual variability that captures our attention here, or were performed at the seasonal scale and using coarser resolution; none of these studies have paid particular attention to the IP.

Figure 10 shows the $\mathrm{NAO}^{-}$minus $\mathrm{NAO}^{+}$composites for SWD as Figs. 2 and 6 provided them for SPD10 and PRE. Obtained $\mathrm{NAO}^{-}$minus $\mathrm{NAO}^{+}$differences in SWD are about $400-600 \mathrm{~W} \mathrm{~m}^{-2}$, exceeding $800 \mathrm{~W} \mathrm{~m}^{-2}$ in March, with the signal-to-noise ratio mostly sustained above 0.75 . As a percentage, the interannual variations in SWD associated with changes in the NAO phase are around $10 \%-20 \%$. The causal chain is that $\mathrm{NAO}^{-}$ enhances cloudiness with consequent dimming (Chiacchio and Wild 2010; Pozo-Vázquez et al. 2011). These signals are well supported by temporal correlations between NAO and SWD (CLW) up to $0.7(-0.7)$ (not shown). The increased cloudiness over many parts of the IP during $\mathrm{NAO}^{-}$may be linked to the more frequent low pressure systems and associated fronts (with many clouds) transporting humid air from the Atlantic, likewise leading to the increase in precipitation. In fact, Chiacchio and Wild (2010) found that the highest correlations between NAO and clouds in southern Europe corresponded to the nimbostratus midlevel clouds, the kind of clouds responsible for the stratiform precipitation associated with cold fronts, which is the most important source of precipitation in Iberia. In agreement with this, we found that the NAO impact on PRE is mainly related to changes in the stratiform nonconvective precipitation rather than changes in convective rainfall (not shown).

Consistently, the patterns in Fig. 10 show spatial distributions similar to those corresponding to the wind and precipitation fields previously described (Figs. 2 and 6). Again, the highest and most spatially extended signals are obtained in December, February, and March, and are particularly intense in the inner and southern regions of the IP, while the smallest are found in October and November, and are more confined to the western half of the IP. Some unusual signals can also be observed. Significant positive $\mathrm{NAO}^{-}$minus $\mathrm{NAO}^{+}$differences in SWD are obtained in two cases: in small eastern coastal areas of the IP and over the Balearic Islands in October, and over a small region in the eastern Cantabrian coast of the IP and north of the Pyrenees in December (which is in concordance with the enhancing $\mathrm{NAO}^{+}$impact on PRE found over the same area/month). 
a) October, NAO-impact, SWD

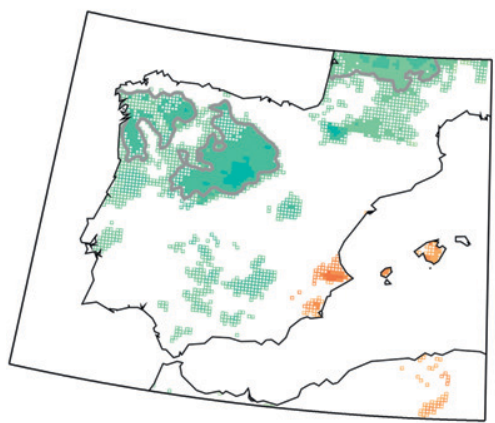

d) January, NAO-impact, SWD

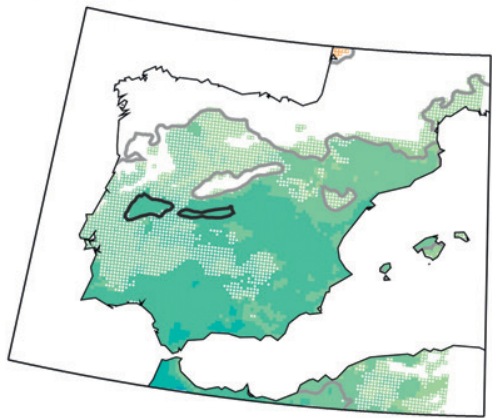

b) November, NAO-impact, SWD

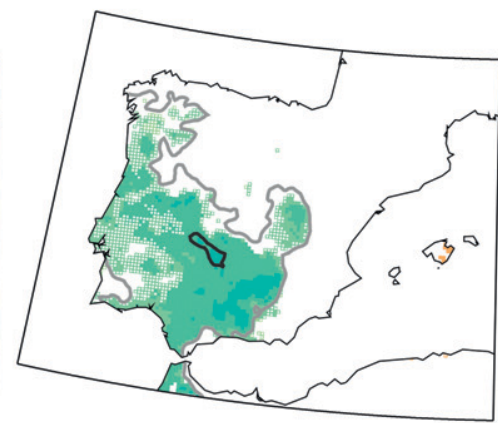

e) February, NAO-impact, SWD

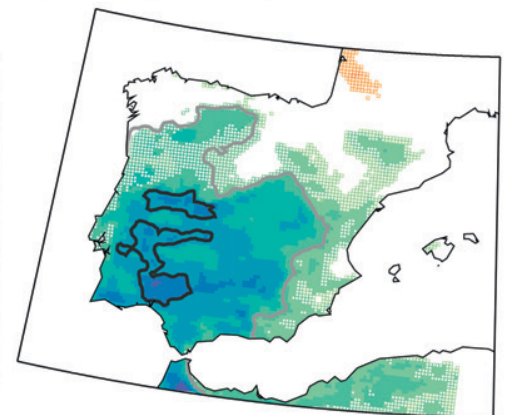

c) December, NAO-impact, SWD

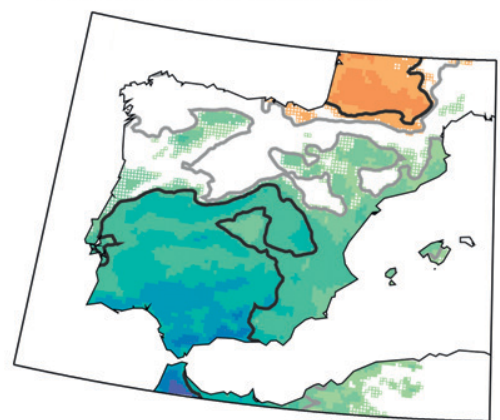

f) March, NAO-impact, SWD

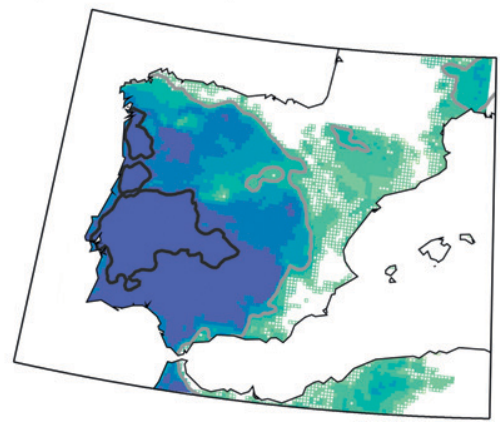

$\left(\mathrm{W} / \mathrm{m}^{2}\right)$

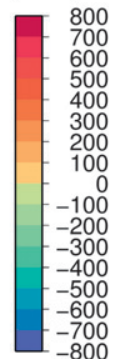

(\%)

FIG. 10. As in Fig. 2, but for SWD $\left(\mathrm{W} \mathrm{m}^{-2}\right)$.

Regarding the NAO impact on the standard deviation of the SWD series, no significant signals were found. This is worth mentioning in the context of the NAOrelated predictability of the resource, as discussed in previous sections.

Therefore, an overall increment in SP is to be expected in months with $\mathrm{NAO}^{+}$. Nevertheless, it should be stressed that the anticyclonic stable conditions over the IP associated with $\mathrm{NAO}^{+}$phases could favor the raise of the aerosol concentrations, which, in turn, would lead to a decrease in sunshine (Sanchez-Lorenzo et al. 2008; Chiacchio and Wild 2010). On the contrary, clearer skies (in terms of aerosol concentrations) during $\mathrm{NAO}^{-}$ would be expected, promoted by facts such as that enhanced precipitation favors wet aerosol deposition. Other mechanisms related to air pollution transport from North America toward Europe may also play important roles (Christoudias et al. 2012). However, these features are not taken into account in our analysis since MM5 does not include atmospheric chemistry, and hence this topic still requires further research.

\section{2) IMPACTS OF NAO ON SP GENERATION}

Solar power is the least mature renewable energy technology in Iberia of the three analyzed in this work. The first large-scale commercial solar plants were deployed by the year 2005 . For this reason, only annual data since
2005 are available. Similarly to Figs. 5 and 9, Fig. 11a depicts the evolution of both SP generation and installed capacity, revealing a general 1-yr lag: the SP generation curve follows the installed SP curve $1 \mathrm{yr}$ after. This could be due to several (unknown) factors, for instance that the installed power is assigned at the beginning of the year while the production is reported for the entire year. Whatever the reason, this fact has been taken into account when computing the normalized SP generation as the ratio between the SP generation and the SP installed capacity of the year before. Despite the scarcity of data, the normalized SP generation series correlate acceptably with the NAO index (Fig. 11b). In particular, the correlation with the January-March averaged NAO series is above 0.6 , which may reflect the strong NAO impact on SWD observed in March. Despite the extremely short period of SP production analyzed, these results further contribute to confirm the important role that the NAO also has on the solar resource.

\section{Conclusions and remarks}

Both Iberian countries are strongly committed to renewable energy as a source of economic development and as part of ongoing strategies designed to mitigate current and future climate change (Jacobson and Delucchi 2009; Gómez et al. 2010; Patel 2011). The main renewable 
a) SPG \& SPI (annual data)

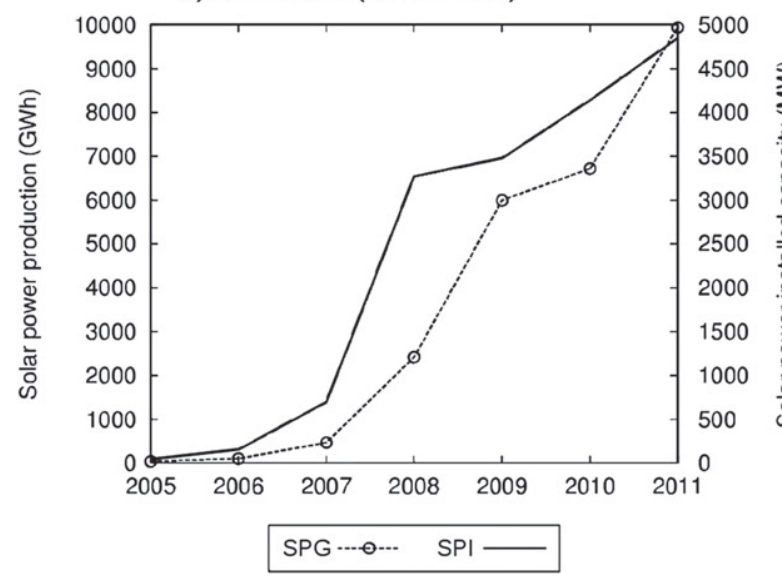

b) NSPG \& NAO (annual data \& more)

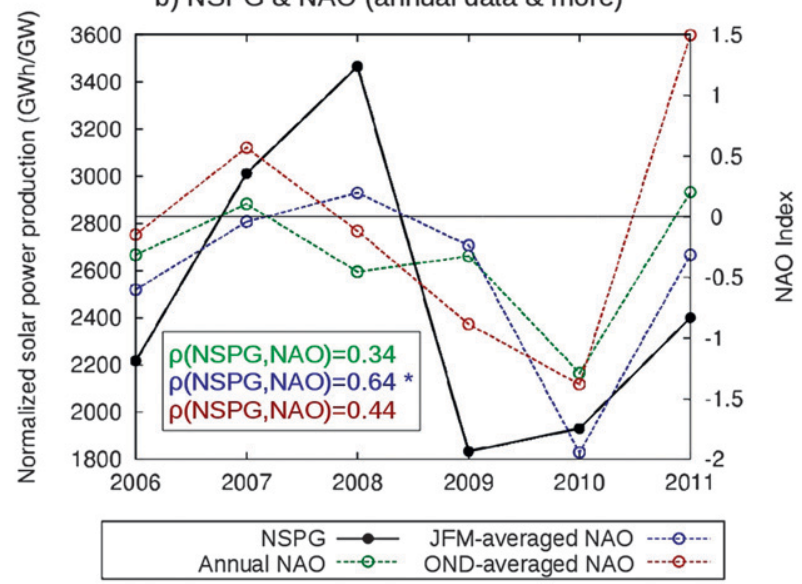

FIG. 11. Temporal series of annual values of (a) solar power generation (SPG; GW h) and solar power installed capacity (SPI; MW) and (b) normalized solar power generation (computed as the generation divided by the installed capacity during the year before) (NSPG; $\mathrm{GW} \mathrm{h} \mathrm{GW}^{-1}$ ) and annual (green), JFM-averaged (blue), and OND-averaged (red) NAO index. The $\rho$ (NSPG, NAO) in (b) is the temporal correlation between the series of NSPG and the corresponding NAO series. The asterisk indicates statistical significance $(p<0.1)$.

energy resources in the Iberian Peninsula, namely wind, hydropower, and solar, are climate dependent and, therefore, are climate-varying resources. Hence, it becomes mandatory to assess and understand the variability of the resources for successful management of renewable energy installations, which is the main goal of this study. In order to overcome the limitations of the scarce (in both time, for climate-related purposes, and space) observational data, we rely here on a regional climate simulation driven by reanalysis and analysis data that covers the whole IP and the surrounding water mass areas with a horizontal resolution of $10 \mathrm{~km}$ spanning the period 1959-2007.

We have focused on the interannual variations of the resources (wind, precipitation, and surface solar radiation) associated with the variations of the North Atlantic Oscillation at the monthly time scale. Despite the complexity of the Iberian climate (Font-Tullot 2000), the NAO mode controls a large amount of its variability as part of western Europe (Hurrell 1995; Osborn et al. 1999; Wanner et al. 2001). Although we are aware that other large-scale teleconnection modes play a role in the IP climate, namely the eastern Atlantic and the Scandinavian patterns (Trigo et al. 2008; Martín et al. 2011), the NAO is the most important atmospheric circulation pattern driving the climate variability in the IP. In fact, observational and coarser studies have already reported a strong NAO impact on the Iberian climate and resources (Rodó et al. 1997; Trigo et al. 2002, 2004, 2008; López-Moreno et al. 2007; Lorenzo-Lacruz et al. 2011; Pozo-Vázquez et al. 2011). As in those previous studies, we obtain the main signals for the winter half of the year; thus, we restricted this work to the October-March months.

Our results are in good agreement with the literature. Overall, negative NAO phases enhance the wind speed (about 10\%-20\% at near-surface levels) and precipitation (above $100 \%$ ), thus promoting the wind power and increasing the river streamflows (i.e., the hydropower potential). On the other hand, as $\mathrm{NAO}^{-}$also enhances cloudiness, it reduces the incoming shortwave solar radiation that reaches the surface (by about $10 \%-20 \%$ ), and thus the solar potential. Consequently, $\mathrm{NAO}^{-}$ events lead to increased wind power and hydroelectric generation, while $\mathrm{NAO}^{+}$events favor the generation of solar power, as confirmed with real generation data. This could suggest, in particular, that a common and optimized design of both solar plants and wind farms (as these correspond to the two most promising renewable energy sectors in the coming decades) could minimize the NAO impact on the total energy production from these two sources, at least on a monthly time scale during the winter half of the year. Moreover, as the NAO strongly drives the Iberian climate variability, this could further suggest that both resources strongly complement each other, which is the subject of a current investigation. Also supporting this finding, the real normalized WP and SP annual series are clearly anticorrelated in their overlapping observational period.

Further extending and updating our previous knowledge, this work provides added value and novel insights because it

1) considers a five-decade-long period that supports the robustness of the results; 
2) guarantees the physical consistency among the results for the various resources, which is derived from the very nature of the database, thus providing a holistic, integrative, and coherent picture of the NAO impacts that can serve as a basis for addressing the challenges of achieving the optimal mix regarding stable and, correlated to the demand, renewable energy generation (Heide et al. 2010; Krajacic et al. 2011; Ruiz-Arias et al. 2012);

3) assesses the NAO impacts with high spatiotemporal detail, allowing us to identify that the largest signals appear in the late winter months in the central, southern, and western (mainly lowland) areas, and to unveil even some striking responses, namely the $\mathrm{NAO}^{+}$-enhanced wind speed in the Ebro River valley and the Strait of Gibraltar in December and March, respectively, and $\mathrm{NAO}^{+}\left(\mathrm{NAO}^{-}\right)$-enhanced precipitation (solar radiation) in the northernmost areas during December;

4) explores the NAO impact on wind direction at a high resolution, providing a robust explanation of the fine features of the NAO impact on wind speed as a result of the large-scale imposed circulation (mainly the $\mathrm{NAO}^{-}$-promoted windy westerly flow west of Iberia) modulated by the local orographic forcing;

5) extends the assessment of the NAO impact on the wind resource at various altitudes, including those that are relevant for the wind turbine placements, highlighting (i) that the spatial distributions of the patterns of the NAO impact on wind speed are very similar regardless of altitude, (ii) the progressive intensification of the NAO impact on wind speed as we move upward in both absolute and relative terms (from $10 \%$ at $15-\mathrm{m}$ height to $15 \%$ at $110-\mathrm{m}$ height in spatial average), and (iii) that the NAO impact on WP would also increase with height in absolute terms, but in relative terms it would drop from over $40 \%$ at the lowest level to around $25 \%$ at the highest level;

6) highlights that as $\mathrm{NAO}^{-}$enhances mean precipitation throughout most of the IP, the response of the precipitation to the $\mathrm{NAO}^{-}$phase is less constrained (more uncertain) than to the $\mathrm{NAO}^{+}$phase, while neither the wind speed nor the solar radiation series show differences in their standard deviations between the $\mathrm{NAO}^{-}$and $\mathrm{NAO}^{+}$class subsets; and

7) includes assessments based on real energy production and reservoir data that largely confirm the expectations from the MM5-based study and further reveal (i) that the winter NAO impact on reservoir storage propagates throughout the year, thus significantly affecting the water management practices in the reservoirs systems (i.e., reservoir releases) and (ii) that even when considering annual aggregated data of energy production, the signature of the NAO can be clearly recognized in the three renewable energies assessed here.

These results may help to improve the medium-range predictability of the renewable energy resources in Iberia (as it could be enhanced by considering forecasts of the NAO index when they were available with sufficient accuracy) and thereby their management from an integrated perspective. In addition, this study provides a basis for the interpretation of future projections and trends of the NAO (although they are still unclear; Cubasch et al. 2001; Hurrell et al. 2003) in terms of the renewable energy potential in the IP and, hence, may be suitable for helping in the design of future energy supply strategies.

Acknowledgments. Sonia Jerez and Ricardo M. Trigo acknowledge the support provided by the Portuguese Science Foundation (FCT) through the ENAC project (PTDC/AAC-CLI/103567/2008). Sergio M. VicenteSerrano and Jorge Lorenzo Lacruz receive support from the following research projects: CGL2011-27574CO2-02 and CGL2011-27536, financed by the Spanish Commission of Science and Technology and "Demonstration and validation of innovative methodology for regional climate change adaptation in the Mediterranean area" (LIFE MEDACC) financed by the LIFE Program of the European Commission. David Pozo Vázquez and Francisco Javier Santos Alamillo acknowledge funding provided by the Consejería de Innovación, Ciencia y Empresa (CICE) of the Junta de Andalusia (Spain) (Project P07-RNM-02872) and the FEDER. Raquel Lorente Plazas and Juan Pedro Montávez Gómez acknowledge support from the Ministerio de Ciencia e Innovación (CGL2011-29672C02-02) and from the Ministerio de Medio Ambiente (Project 200800050084265). Finally, the authors thank the anonymous reviewers for the valuable feedback they provided.

\section{APPENDIX A}

\section{MM5 Simulation of Meteorological Fields}

The hindcast regional climate simulation was performed with a climate version of the MM5 (Grell et al. 1994), which has previously been used in others works (Jerez et al. 2010, 2012a). Two two-way nested domains with spatial resolutions of $10 \mathrm{~km}$ in the inner domain, which covers the whole IP, and $30 \mathrm{~km}$ in the outer domain (Fig. A1), and 27 inhomogeneous vertical sigma levels (more closely spaced near the surface) with the 


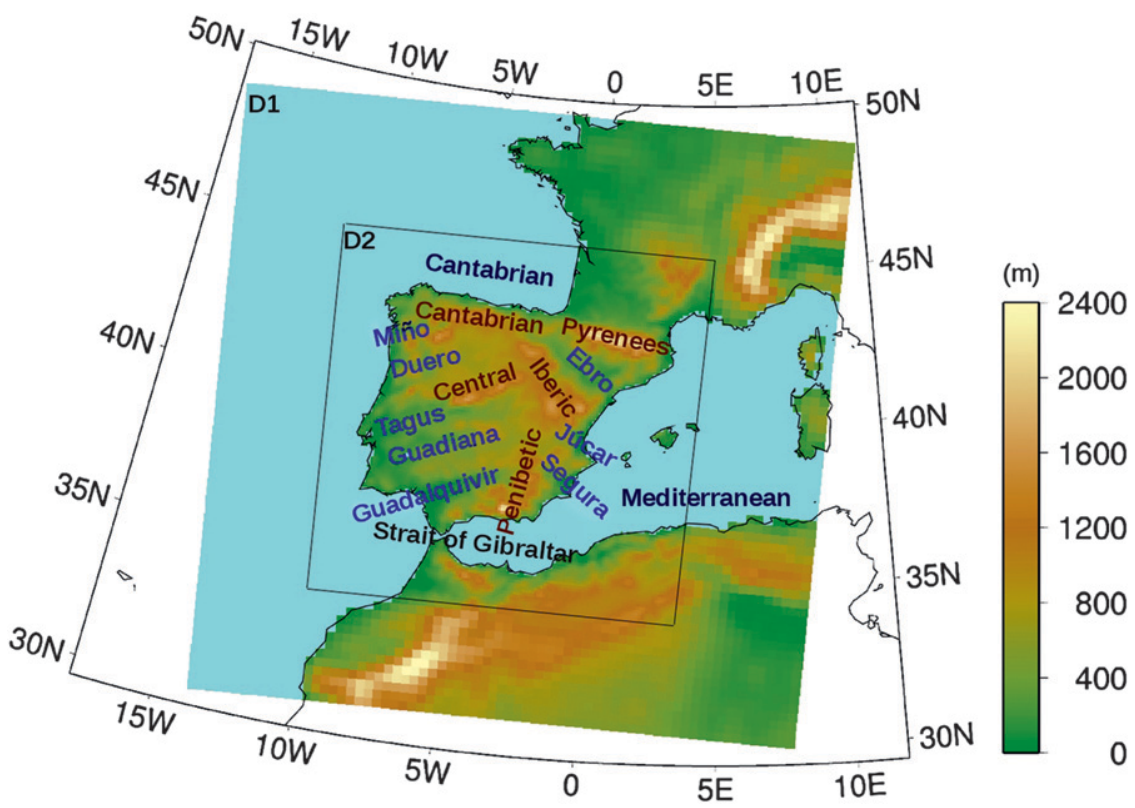

FIG. A1. Domain configuration used in the MM5 simulation. The outer domain (D1) has a resolution of $30 \mathrm{~km}$, and the inner domain (D2), which covers the whole IP, has a resolution of $10 \mathrm{~km}$. The topography "seen" by the model at these resolutions is depicted by color shades (height above the sea level; $\mathrm{m}$ ). The names and locations of seas (dark blue), main river basins (light blue) and mountain systems (brown), and the Strait of Gibraltar (black) are indicated.

top at $100 \mathrm{hPa}$ were considered. The parameterization schemes employed within MM5 were the Rapid Radiative Transfer Model radiation scheme (Mlawer et al. 1997), the Grell cumulus scheme (Grell 1993), the simple ice microphysics parameterization (Dudhia 1989), the Medium-Range Forecast planetary boundary layer scheme (Hong and Pan 1996), and the comprehensive Noah land surface model (Chen and Dudhia 2001), as suggested by previous tests (Jerez et al. 2012b). The simulation spans the period 1959-2007. It was initialized and driven at the domain boundaries using the 40-yr European Centre for Medium-Range Weather Forecasts (ECMWF) Re-Analysis (ERA-40; Uppala et al. 2005 ) for the period in which it is available (i.e., 19592002) and analysis data from ECMWF for the remaining period (2003-07). The boundary conditions were updated every $6 \mathrm{~h}$. The outputs were recorded every hour.

A first study (Lorente-Plazas et al. 2012) showed the reliability of the simulated wind field by comparison with an observational database that includes 450 stations evenly distributed over the Iberian Peninsula and spans the period 1999-2007. The results indicated that the simulation is well able to reproduce the main regional circulation patterns as well as the temporal variability of the wind series, with the largest errors involving an overall overestimation of the wind speed in eastern
Iberia. A future study, which is currently in preparation, will be entirely devoted to the validation of the simulated wind field from the hourly to the seasonal time scales. Here, we provide a short validation aimed at illustrating the former statements (Fig. A2). The locations chosen are representative of the various wind regimes obtained through a clustering-based analysis. It can be seen that generally the simulated monthly wind speed series have small biases (under $25 \%$, with the exception of the series in the Mediterranean area) and similar amplitude compared with the observational series (with the standard deviation ratio being between 0.7 and 1.2 in the majority of the cases). Additionally, the correlations between both series often reach 0.9. Figure A2 also provides the wind roses obtained from the hourly series of wind direction. While some discrepancies can be recognized, the observed prevailing directions are in general properly simulated. Given the high sensitivity of both the wind speed and direction, and their measurement systems, to very local features (which could even have changed along the observational period) that are not represented in the modeling system due to its very nature, these results support a remarkable reliability of the simulated wind field.

For completeness, a validation of the simulated precipitation (PRE) and daily maximum and minimum temperature ( $T_{\max }$ and $T_{\min }$ ) fields by comparison with 


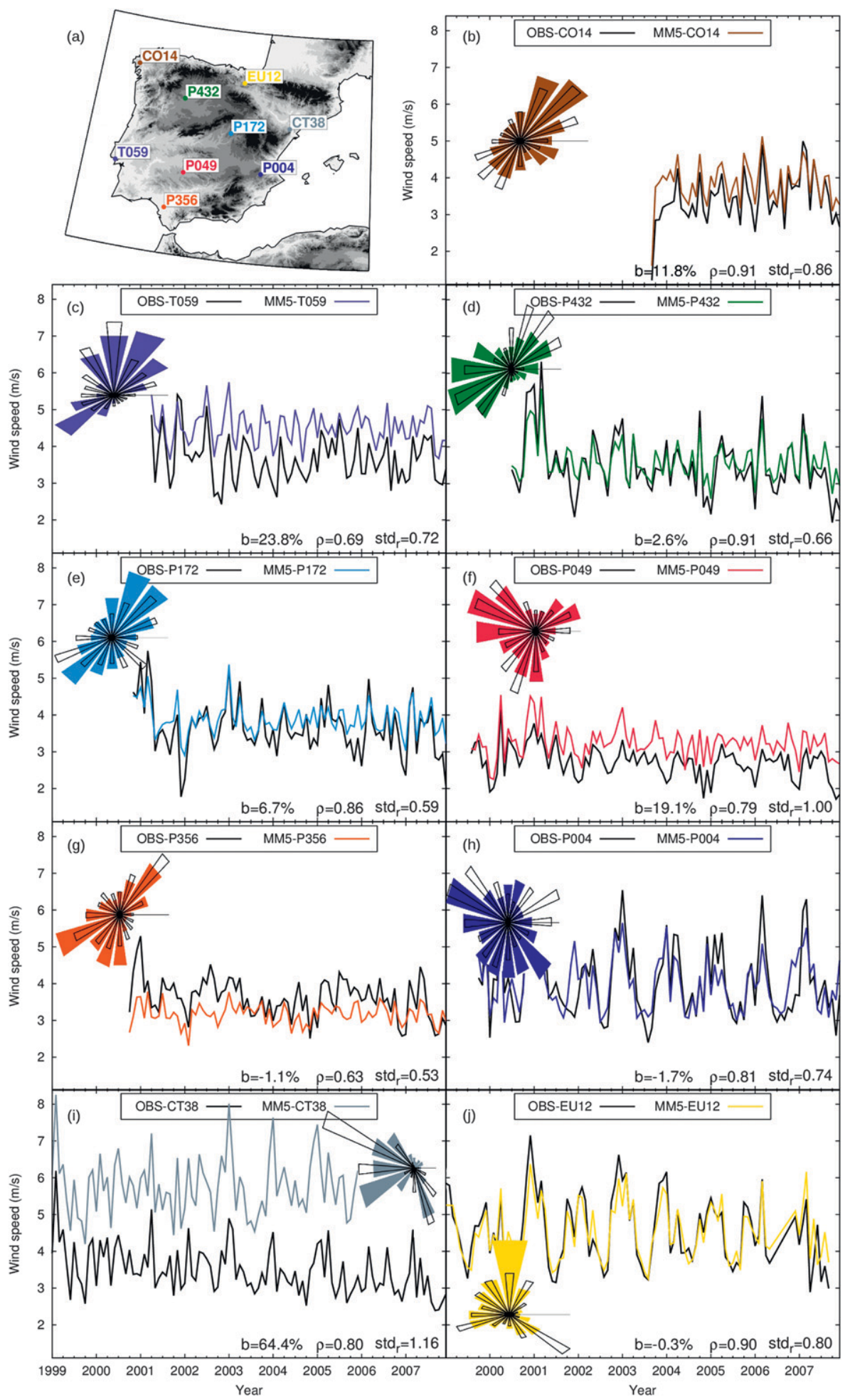

FIG. A2. (a) The color-coded locations of the observations (OBS). (b)-(j) Comparison of the MM5-simulated 10-m monthly wind series (colored lines) with the OBS (black lines). The values of the mean bias $b$ of the simulated series (\%), the temporal correlation $\rho$ between the simulated and the observational series, and the ratio $\operatorname{std}_{r}$ between the standard deviation of the simulated series and the standard deviation of the observed series are given for each station. The wind roses from the observational (open black) and the simulated (filled colors) hourly series of wind direction are also shown. The nominal observational period is 1999-2007. However, some observational series start later. 
TABLE A1. Validation of the hindcast database by comparison with Spain02. Shown are the temporal correlation between the simulated and the observed spatially averaged monthly series $\left(\rho_{T}\right)$ and the spatial correlation between the simulated and the observed monthly patterns $\left(\rho_{S}\right)$ of each variable (PRE, $T_{\max }$, and $\left.T_{\min }\right)$ for each month separately. Period considered is 1959-2007.

\begin{tabular}{|c|c|c|c|c|c|c|}
\hline & \multicolumn{2}{|c|}{ PRE } & \multicolumn{2}{|c|}{$T_{\max }$} & \multicolumn{2}{|c|}{$T_{\min }$} \\
\hline & $\rho_{T}$ & $\rho_{S}$ & $\rho_{T}$ & $\rho_{S}$ & $\rho_{T}$ & $\rho_{S}$ \\
\hline Oct & 0.96 & 0.87 & 0.95 & 0.96 & 0.96 & 0.93 \\
\hline Nov & 0.95 & 0.86 & 0.93 & 0.96 & 0.94 & 0.93 \\
\hline Dec & 0.95 & 0.83 & 0.94 & 0.94 & 0.96 & 0.92 \\
\hline Jan & 0.96 & 0.84 & 0.91 & 0.94 & 0.93 & 0.91 \\
\hline Feb & 0.95 & 0.84 & 0.95 & 0.96 & 0.97 & 0.92 \\
\hline Mar & 0.97 & 0.83 & 0.95 & 0.96 & 0.95 & 0.91 \\
\hline Apr & 0.94 & 0.83 & 0.93 & 0.96 & 0.96 & 0.93 \\
\hline May & 0.91 & 0.87 & 0.96 & 0.96 & 0.96 & 0.9 \\
\hline Jun & 0.89 & 0.87 & 0.96 & 0.95 & 0.96 & 0.93 \\
\hline Jul & 0.85 & 0.90 & 0.91 & 0.94 & 0.92 & 0.91 \\
\hline Aug & 0.77 & 0.89 & 0.91 & 0.95 & 0.95 & 0.90 \\
\hline Sep & 0.89 & 0.87 & 0.96 & 0.96 & 0.94 & 0.92 \\
\hline
\end{tabular}

the gridded observational database Spain02 (Herrera et al. 2012; http://www.meteo.unican.es/es/datasets/ spain02) was performed at the monthly time scale. This comparison is restricted to Spanish territory, since Spain02 does not extend to Portugal. It was performed after the interpolation of the simulated fields from the MM5 grid onto the $0.2^{\circ} \times 0.2^{\circ}$ observational Spain02 grid. Note that the variables Tmax and Tmin are closely related to SWD and CLW, as these latter terms control the surface radiation budget. Thus, a good level of model performance regarding the former variables is required in order to assume that the model operates correctly regarding the latter, although this does not however provide a $100 \%$ conclusive proof. Since possible systematic biases do not represent a major concern for the assessment provided in this work (as it involves differences in mean fields), this validation focuses on temporal correlations between spatially averaged series $\left(\rho_{T}\right)$ and spatial correlations between monthly patterns $\left(\rho_{S}\right)$ (Table A1). Obtained results demonstrate that the interannual variability of the spatially averaged series is reproduced accurately, with $\rho_{T}$ amply above 0.9 for all the variables in the great majority of the months, particularly during all the winter months. On the other hand, $\rho_{S}$ is around 0.85 for PRE, slightly above 0.9 for Tmin, and about 0.95 for Tmax for all months, which proves the reliability of the spatial distribution of the simulated patterns.

These results make us confident in the suitability of this database for the purposes of this study, being aware that its representativeness should not be considered at the local but at the regional spatial scale.

\section{APPENDIX B}

\section{Glossary of Key Acronyms}

CLW Column-integrated cloud water

DIR Wind direction (the suffix 10 indicates that it is at $10-\mathrm{m}$ height)

HP Hydropower

IP Iberian Peninsula

NAO North Atlantic Oscillation

PRE Precipitation (the suffix sdev indicates that it refers to the standard deviation of the precipitation series)

SP Solar power

SPD Wind speed (the suffix 10 indicates that it is at 10-m height)

SWD Surface shortwave downward radiation

WP Wind power

\section{REFERENCES}

Caldés, N., M. Varela, M. Santamaría, and R. Sáez, 2009: Economic impact of solar thermal electricity deployment in Spain. Energy Policy, 37, 1628-1636.

Campo, A., 1992: Status and trends in Spanish hydropower production. Int. Water Power Dam Constr., 44, 30-32.

Chen, F., and J. Dudhia, 2001: Coupling an advanced land surfacehydrology model with the Penn State-NCAR MM5 modeling system. Part I: Model implementation and sensitivity. Mon. Wea. Rev., 129, 569-585.

Chiacchio, M., and M. Wild, 2010: Influence of NAO and clouds on long-term seasonal variations of surface solar radiation in Europe. J. Geophys. Res., 115, D00D22, doi: 10.1029/ 2009JD012182.

Christensen, J. H., B. Machenhauer, R. G. Jones, C. Schär, P. M. Ruti, M. Castro, and G. Visconti, 1997: Validation of present-day climate simulations over Europe: LAM simulations with observed boundary conditions. Climate Dyn., 13, 489-506.

Christoudias, T., A. Pozzer, and J. Lelieveld, 2012: Influence of the North Atlantic Oscillation on air pollution transport. Atmos. Chem. Phys., 12, 869-877.

Cubasch, U., and Coauthors, 2001: Projections of future climate change. Climate Change 2001: The Scientific Basis, J. T. Houghton et al., Ed., Cambridge University Press, 525-582.

Dorman, C. E., R. C. Beardsley, and R. Limeburner, 1995: Winds in the Strait of Gibraltar. Quart. J. Roy. Meteor. Soc., 121, 1903-1921.

Dudhia, J., 1989: Numerical study of convection observed during the Winter Monsoon Experiment using a mesoscale twodimensional model. J. Atmos. Sci., 46, 3077-3107.

Echavarria, E., B. Hahn, G. J. W. Van Bussel, and T. Tomiyama, 2008: Reliability of wind turbine technology through time. J. Sol. Energy Eng., 130, 031005, doi:10.1115/1.2936235.

Esteban-Parra, M. J., F. S. Rodrigo, and Y. Castro-Díez, 1998: Spatial and temporal patterns of precipitation in Spain for the period 1880-1992. Int. J. Climatol., 18, 1557-1574.

Font-Tullot, I., 2000: Climatología de España y Portugal. Universidad de Salamanca, $422 \mathrm{pp}$. 
Gallego, M. C., J. A. García, and J. M. Vaquero, 2005: The NAO signal in daily rainfall series over the Iberian Peninsula. Climate Res., 29, 103-109.

Giorgi, F., 2006: Climate change hot-spots. Geophys. Res. Lett., 33, L08707, doi:10.1029/2006GL025734.

Gómez, A., J. Zubizarreta, C. Dopazo, and N. Fueyo, 2010: Spanish energy roadmap to 2020: Socioeconomic implications of renewable targets. Energy, 36, 1973-1985.

Gomez-Navarro, J. J., J. P. Montavez, S. Jerez, P. Jimenez-Guerrero, R. Lorente-Plazas, J. F. González-Rouco, and E. Zorita, 2011: A regional climate simulation over the Iberian Peninsula for the last millennium. Climate Past, 7, 451-472.

Grell, G. A., 1993: Prognostic evaluation of assumptions used by cumulus parameterizations. Mon. Wea. Rev., 121, 764787.

_ J. Dudhia, and D. R. Stauffer, 1994: A description of the fifthgeneration Penn State/NCAR Mesoscale Model (MM5). NCAR Tech. Note NCAR/TN-398+STR, 117 pp.

Heide, D., L. Von Bremen, M. Greiner, C. Hoffmann, M. Speckmann, and S. Bonger, 2010: Seasonal optimal mix of wind and solar power in a future, highly renewable Europe. Renew. Energy, 35, 2483-2489.

Herrera, S., L. Fita, J. Fernandez, and J. M. Gutierrez, 2010: Evaluation of the mean and extreme precipitation regimes from the ENSEMBLES regional climate multimodel simulations over Spain. J. Geophys. Res., 115, D21117, doi:10.1029/ 2010JD013936.

—, J. M. Gutierrez, R. Ancell, M. R. Pons, M. D. Frias, and J. Fernandez, 2012: Development and analysis of a 50 year high-resolution daily gridded precipitation dataset over Spain (Spain02). Int. J. Climatol., 32, 74-85.

Hong, S.-Y., and H.-L. Pan, 1996: Nonlocal boundary layer vertical diffusion in a medium-range forecast model. Mon. Wea. Rev., 124, 2322-2339.

Hughes, M., A. Hall, and R. G. Fovell, 2009: Blocking in areas of complex topography and its influence on rainfall distribution. J. Atmos. Sci., 66, 508-518.

Hurrell, J., 1995: Decadal trends in North Atlantic Oscillation and relationship to regional temperature and precipitation. Science, 269, 676-679.

— ciated with the North Atlantic Oscillation. Climatic Change, 36, 301-326.

—, Y. Kushnir, G. Ottersen, and M. Visbeck, 2003: The North Atlantic Oscillation. Climatic Significance and Environmental Impact. Geophys. Monogr., Vol. 134, Amer. Geophys. Union, $279 \mathrm{pp}$

Jacobson, M., and M. Delucchi, 2009: A path to sustainable energy by 2030. Sci. Amer., 301, 58-65.

Jerez, S., J. P. Montavez, J. J. Gomez-Navarro, P. Jimenez-Guerrero, J. Jimenez, and J. F. Gonzalez-Rouco, 2010: Temperature sensitivity to the land-surface model in MM5 climate simulations over the Iberian Peninsula. Meteor. Z., 19, 363-374.

,,,--- P. A. Jimenez, P. Jimenez-Guerrero, R. LorentePlazas, and J. F. Gonzalez-Rouco, 2012a: The role of the landsurface model for climate change projections over the Iberian Peninsula. J. Geophys. Res., 117, D01109, doi:10.1029/ 2011JD016576.

— _ — P. Jimenez-Guerrero, J. J. Gomez-Navarro, R. LorentePlazas, and E. Zorita, 2012b: A multi-physics ensemble of present-day climate regional simulations over the Iberian Peninsula. Climate Dyn., 40, 3023-3046, doi:10.1007/ s00382-012-1539-1.
Jimenez, P., O. Jorba, R. Parra, and J. M. Baldasano, 2006: Evaluation of MM5-EMICAT2000-CMAQ performance and sensitivity in complex terrain: High-resolution application to the northeastern Iberian Peninsula. Atmos. Environ., 40, 50565072.

Kanamitsu, M., W. Ebisuzaki, J. Woollen, S.-K. Yang, J. J. Hnilo, M. Fiorino, and G. L. Potter, 2002: NCEP-DOE AMIP-II Reanalysis (R-2). Bull. Amer. Meteor. Soc., 83, 1631-1643.

Krajacic, G., N. Duic, and M. Carvalho, 2011: How to achieve a 100\% RES electricity supply for Portugal? Appl. Energy, 88 , 508-517.

López-Moreno, J. I., and S. M. Vicente-Serrano, 2008: Extreme phases of the wintertime North Atlantic Oscillation and drought occurrence over Europe: A multi-temporal-scale approach. J. Climate, 21, 1220-1243.

— S. Beguería, S. M. Vicente-Serrano, and J. M. García-Ruiz, 2007: The influence of the NAO on water resources in central Iberia: Precipitation, streamflow anomalies and reservoir management strategies. Water Resour. Res., 43, W09411, doi:10.1029/2007WR005864.

Lorente-Plazas, R., and Coauthors, 2012: EOLMAP: A web tool to assess the wind resource over Spain. Int. Conf. on Renewable Energies and Power Quality, Santiago de Compostela, Spain, European Association for the Development of Renewable Energies, Environment and Power Quality, 95-105.

Lorenzo-Lacruz, J., S. M. Vicente-Serrano, J. I. López-Moreno, S. Beguería, J. M. García-Ruiz, and J. M. Cuadrat, 2010: The impact of droughts and water management on various hydrological systems in the headwaters of the Tagus River (central Spain). J. Hydrol., 386, 13-26.

,,,--- J. C. González-Hidalgo, and E. Morán-Tejeda, 2011: The response of Iberian rivers to the North Atlantic Oscillation. Hydrol. Earth Syst. Sci., 15, 2581-2597.

$-, \ldots,-$ E. Morán-Tejeda, and J. Zabalza, 2012: Recent trends in Iberian streamflows (1945-2005). J. Hydrol., 414415, 463-475.

Martín, M. L., F. Valero, A. Morata, M. Y. Luna, A. Pascual, and D. Santos-Muñoz, 2010: Springtime coupled modes of regional wind in the Iberian Peninsula and large-scale variability patterns. Int. J. Climatol., 31, 880-895.

,,-- A. Pascual, A. Morata, and M. Y. Luna, 2011: Springtime connections between the large-scale sea-level pressure field and gust wind speed over Iberia and the Balearics. Nat. Hazards Earth Syst., 11, 191-203.

Mlawer, E. J., S. J. Taubman, P. D. Brown, M. J. Iacono, and S. A. Clough, 1997: Radiative transfer for inhomogeneous atmospheres: RRTM, a validated correlated- $k$ model for the longwave. J. Geophys. Res., 102, 16663-16682.

Morán-Tejeda, E., J. I. López-Moreno, A. Ceballos-Carbancho, and S. M. Vicente-Serrano, 2011: Streamflow response to positive and negative phases of the North Atlantic Oscillation in the Duero basin (central-Spain): Spatial variability and response times. Hydrol. Processes, 25, 1313-1326.

Muñoz-Díaz, D., and F. S. Rodrigo, 2003: Effects of the North Atlantic Oscillation on the probability for climatic categories of local monthly rainfall in southern Spain. Int. J. Climatol., 23, 381-397.

Osborn, T. J., K. R. Briffa, S. F. B. Tett, P. D. Jones, and R. M. Trigo, 1999: Evaluation of the North Atlantic Oscillation as simulated by a coupled climate model. Climate Dyn., 15, 685-702.

Palutikof, J. P., P. M. Kelly, T. D. Davies, and J. A. Halliday, 1987: Impacts of spatial and temporal wind speed variability on wind energy output. J. Appl. Meteor., 26, 1124-1133. 
Paredes, D., R. M. Trigo, R. Garcia-Herrera, and I. F. Trigo, 2006: Understanding precipitation changes in Iberia in early spring: Weather typing and storm-tracking approaches. J. Hydrometeor., 7, 101-113.

Patel, S., 2011: Spain: A renewable kingdom. Power Policy, June, 30-37. [Available online at http://www.powermag.com/ business/3722.html.]

Pires, C. A., and R. A. P. Perdigão, 2007: Non-Gaussianity and asymmetry of the winter monthly precipitation estimation from the NAO. Mon. Wea. Rev., 135, 430-448.

Pozo-Vázquez, D., J. Tovar-Pescador, S. R. Gámiz-Fortis, M. J. Esteban-Parra, and Y. Castro-Díez, 2004: NAO and solar radiation variability in the European North Atlantic region. Geophys. Res. Lett., 31, L05201, doi:10.1029/2003GL018502.

_ , F. J. Santos-Alamillos, V. Lara-Fanego, J. A. Ruiz-Arias, and J. Tovar-Pescador, 2011: The impact of the NAO on the solar and wind energy resources in the Mediterranean area. $A d$ vances in Global Change Research: Hydrological, Socioeconomic and Ecological Impacts of the North Atlantic Oscillation in the Mediterranean Region, S. M. Vicente-Serrano and R. M. Trigo, Eds., Springer, 213-231.

Rodó, X., E. Baert, and F. A. Comin, 1997: Variations in seasonal rainfall in southern Europe during the present century: Relationships with the North Atlantic Oscillation and the El Niño-Southern Oscillation. Climate Dyn., 13, 275-284.

Rodrigo, F. S., M. J. Esteban-Parra, D. Pozo-Vázquez, and Y. Castro-Díez, 2000: Rainfall variability in southern Spain on decadal to centennial times scales. Int. J. Climatol., 20, 721-732.

Ruiz-Arias, J. A., J. Terrados, P. Pérez-Higueras, D. PozoVázquez, and G. Almonacid, 2012: Assessment of the renewable energies potential for intensive electricity production in the province of Jaén, southern Spain. Renew. Sustainable Energy Rev., 16, 2994-3001.

Salzmann, N., C. Frei, P. Vidale, and M. Hoelzle, 2007: The application of Regional Climate Model output for the simulation of high-mountain permafrost scenarios. Global Planet. Change, 56, 188-202.

Sanchez-Lorenzo, A., J. Calbó, and J. Martin-Vide, 2008: Spatial and temporal trends in sunshine duration over western Europe (1938-2004). J. Climate, 21, 6089-6098.

Snedecor, G. W., and W. G. Cochran, 1989: Statistical Methods. Iowa State University Press, 503 pp.

Stenzel, T., and A. Frenzel, 2008: Regulating technological change-The strategic reactions of utility companies towards subsidy policies in the German, Spanish and UK electricity markets. Energy Policy, 36, 2645-2657.

Tapiador, F. J., 2009: Assessment of renewable energy potential through satellite data and numerical models. Energy Environ. Sci., 2, 1142-1161.

Trigo, I. F., 2006: Climatology and interannual variability of stormtracks in the Euro-Atlantic sector: A comparison between ERA-40 and NCEP/NCAR reanalyses. Climate Dyn., 26, 127143.

Trigo, R. M., 2011: The impacts of the NAO on hydrological resources of the western Mediterranean. Advances in Global Change Research: Hydrological, Socioeconomic and Ecological Impacts of the North Atlantic Oscillation in the Mediterranean Region, S. M. Vicente-Serrano and R. M. Trigo, Eds., Springer, 41-56.

_, T. J. Osborn, and J. M. Corte-Real, 2002: The North Atlantic Oscillation influence on Europe: Climate impacts and associated physical mechanisms. Climate Res., 20, 9-17.

, D. Pozo-Vázquez, T. J. Osborn, Y. Castro-Díez, S. GámizForti, and M. J. Esteban-Parra, 2004: North Atlantic Oscillation influence on precipitation, river flow and water resources in the Iberian Peninsula. Int. J. Climatol., 24, 925-944.

—, M. A. Valente, I. F. Trigo, P. M. A. Miranda, A. M. Ramos, D. Paredes, and R. García-Herrera, 2008: The impact of North Atlantic wind and cyclone trends on European precipitation and significant wave height in the Atlantic. Ann. N.Y. Acad. Sci., 1146, 212-234.

Ulbrich, U., and M. Christoph, 1999: A shift of the NAO and increasing storm track activity over Europe due to anthropogenic greenhouse gas forcing. Climate Dyn., 15, 551559.

Uppala, S. M., and Coauthors, 2005: The ERA-40 Re-Analysis. Quart. J. Roy. Meteor. Soc., 131, 2961-3012.

Wanner, H., S. Brönnimann, C. Casty, D. Gyalistras, J. Luterbacher, C. Schmutz, D. B. Stephenson, and E. Xoplaki, 2001: North Atlantic Oscillation-Concepts and studies. Surv. Geophys., 22, 321-382.

Wernli, H., and C. Schwierz, 2006: Surface cyclones in the ERA-40 dataset (1958-2001). Part I: Novel identification method and global climatology. J. Atmos. Sci., 63, 2486-2507.

Zorita, E., V. Kharin, and H. von Storch, 1992: The atmospheric circulation and sea surface temperature in the North Atlantic area in winter: Their interaction and relevance for Iberian precipitation. J. Climate, 5, 1097-1108. 